\title{
Universiteit
}

Leiden

The Netherlands

\section{Copper mining in Streptomyces: enzymes, natural products and} development

Worrall, J.A.R.; Vijgenboom, E.

\section{Citation}

Worrall, J. A. R., \& Vijgenboom, E. (2010). Copper mining in Streptomyces: enzymes, natural products and development. Natural Product Reports, 27(5), 742-756. doi:10.1039/b804465c

Version: $\quad$ Publisher's Version

License: $\quad$ Licensed under Article 25fa Copyright Act/Law (Amendment Taverne)

Downloaded from: https://hdl.handle.net/1887/3209714

Note: To cite this publication please use the final published version (if applicable). 


\title{
Copper mining in Streptomyces: enzymes, natural products and development $\dagger$
}

\author{
Jonathan A. R. Worrall ${ }^{* a}$ and Erik Vijgenboom ${ }^{* b}$ \\ Received 30th November 2009 \\ First published as an Advance Article on the web 6th April 2010 \\ DOI: $10.1039 / b 804465 c$
}

Covering: up to the end of 2009

\begin{abstract}
The actinobacteria of the genus Streptomyces are of immense importance to both ecological and human welfare. They produce a large number of enzymes and compounds such as antibiotics that have attracted the interest of industry over recent decades, resulting in their commercial manufacture and application in many products. Furthermore, Streptomyces is one of the model systems for bacterial morphological and physiological development. A role for copper proteins and enzymes in the morphological development and in the production of certain secondary metabolites in Streptomyces species has been known for some time. This review summarizes the copper proteins and enzymes identified so far in Streptomyces species, and highlights our current knowledge of the roles some of these proteins play in morphological development and secondary metabolite production.
\end{abstract}

1

2

3

4

5

6

7

8

9

9.1

9.2

10

10.1 Small laccase (SCO6712)

10.2 Lipocyanin (SCO7674)

10.3 A radical copper oxidase (SCO2837)

11 Copper trafficking and development

11.1 Tyrosinase and its copper chaperone

11.2 Copper efflux systems and transcriptional regulators

11.3 The role of Sco1 in copper-dependent development

12 Conclusions and future perspectives

13 References

\section{Life cycle and morphology of Streptomyces}

The class of actinobacteria contains many members that have attracted attention over the years due to their diversity, complex life cycles and production of secondary metabolites. The filamentous Gram-positive soil-dwelling bacterium Streptomyces is a typical example that has an interesting life cycle, resembling in certain aspects that of lower eukaryotes such as fungi (Fig. 1). The reproductive form consists of spores that upon initiation of development produce two germ tubes, the start of a vegetative mycelium. Growth in this mycelium takes place through tip extension and branching resulting in a network of hyphae (Fig. 1C). Septation at irregular intervals divides the vegetative mycelium into compartments. The next phase of morphogenesis consists of the erection of an aerial mycelium. During this process the vegetative mycelium turns into a substrate mycelium, providing the nutrients for the aerial hyphae construction. This step in morphogenesis has many characteristics of programmed cell death. ${ }^{1-4}$ Following the production of the aerial mycelium, a new phase of cell division takes place where septa are positioned at regular intervals preparing the separation of the aerial hyphae in spores. Major players in this event are the proteins belonging to the SsgA-Like Protein (SALP) family that are involved in the control of morphogenesis and the correct assembly of the cell division complexes. ${ }^{5}$ The life cycle is completed with the maturation of the spores. Once released from the spore chains and dispersed in the environment, germination of each spore will result in a new mycelium.

\section{Developmental mutants}

Colchester, CO4 3SO, UK. E-mail: jworrall@essex.ac.uk: Tel: +44 1206 872095

${ }^{b}$ Molecular Biotechnology, Leiden Institute of Chemistry, PO box 9502, 2300RA Leiden, The Netherlands.E-mail:vijgenbo@chem.leiden.nl; Tel. $+31715274278$

$\uparrow$ This paper is part of an NPR themed issue on Metals in cells, guest-edited by Emma Raven and Nigel Robinson.
The various stages of differentiation during growth on solid media can easily be identified with the naked eye, since the formation of aerial hyphae gives colonies a white and fluffy appearance, whereas upon spore formation the color changes 
due to the production of a spore pigment, in general grey (Fig. 1B).

Over the years many proteins have been identified that are involved in one of the developmental switches. The bld mutants are not capable of producing an aerial mycelium (bald) while the whi mutants lack the typical spore pigment and in many cases do not produce spores. Many of the bld mutants are transcription factors such as $b l d G^{6}$ and $b l d N,{ }^{7}$ while $b l d A$ is directly involved in translation because it encodes the tRNA for the rare TTA codon. ${ }^{8,9}$ The bldA mutant demonstrated also a direct link between the intracellular control of development and proteolytic activity in the extracellular proteome. ${ }^{10}$

One of the best-known examples of the genes involved in the switch from aerial mycelium to spore production are the whiE mutants, ${ }^{11}$ which affect the locus that contains the genes for the production of the spore pigment that has resemblance to the polyketides. However, these mutants are from a morphological point of view not defective. Many other loci that encode whi genes have been found, but they are in general not as well characterized as the bld genes. ${ }^{12,13}$

An example of a developmental gene not identified through classical mutagenesis programmes is $s s g A$, encoding for a small protein with unknown function. First identified in $S$. griseus as the suppressor of submerged sporulation, ${ }^{14}$ the orthologue was later also found in $S$. coelicolor. ${ }^{15}$ Disruption of $s s g A$ resulted in a mutant defective in spore formation but capable of aerial hyphae production, and therefore $s s g A$ classifies as a whi gene. Over-expression of SsgA stimulates the septum formation in liquid-grown cultures demonstrating a function of SsgA in cell division. Later, a number of paralogues were identified in $S$. coelicolor, all somehow active in cell division. ${ }^{16}$

The erection of an aerial mycelium requires the hyphae to break through the surface of the water-layer surrounding the hyphae. An elegant model for this process has been proposed on the basis of observations made for mutants of the rodlin and chaplin genes. The products of these morphogenes create amyloid-like fibrils forming the hydrophobic environment that is needed to enable hyphae to have the necessary hydrophilic nature to become airborne. ${ }^{17-19}$

\section{Secondary metabolites}

Concomitant with (or just before) the morphological switch from vegetative to aerial mycelium, the metabolic development is initiated with the production of secondary metabolites. These compounds were probably the main initiators of the scientific interest in Streptomyces because they comprise a large percentage of the clinically useful antibiotics, antifungals and even some of the antitumor agents used to-date. The microbial secondary metabolites have become very important both from an economic and a healthcare point of view. ${ }^{20}$ The onset of the physiological differentiation in streptomycetes, production of secondary metabolites, is intimately associated with the start of morphological development, suggesting that these two processes share common regulatory elements. As for the morphogenesis, the physiological differentiation can be monitored easily because some of the secondary metabolites are pigmented.

The genome of $S$. coelicolor contains the information for at least 23 gene clusters predicted to direct the production of a wide range of secondary metabolites. ${ }^{21}$ Not all of these secondary metabolites have been detected or isolated, suggesting that some of the synthesis clusters may be dormant/cryptic. The recent discovery of a master switch, DasR, that controls a large number of nutrient related processes in Streptomyces including the production of secondary metabolites, may offer the possibility to 'wake-up' these cryptic clusters and produce new secondary metabolites. ${ }^{22}$ Understanding the control of the developmental programme governing the production of secondary metabolites has been a major effort. Many of the regulatory proteins have been shown to participate in intracellular and extracellular signal transduction..$^{23}$ Among these regulators are factors that provide a direct link between bioavailability of metals and secondary metabolite control. Two very recent examples have highlighted

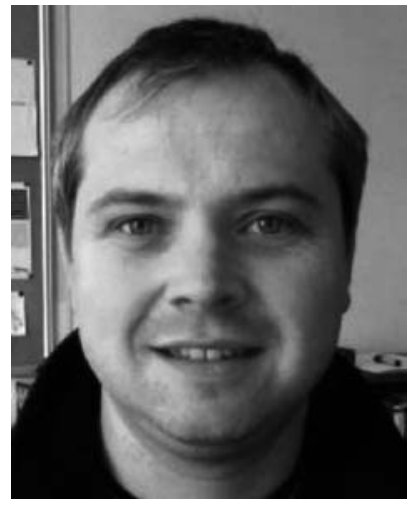

Jonathan Worrall
Jonathan Worrall graduated in 1995 from the University of Newcastle-upon-Tyne with his BSc in Medicinal Chemistry. He pursued a PhD in metalloproteins under the supervision of Prof. Geoff Sykes FRS. Following his PhD training he undertook post-doctoral studies in the metalloprotein group at Leiden University (The Netherlands) working with Prof. Gerard Canters and Dr Marcellus Ubbink. In 2005 he returned to the UK as a post-doctoral fellow at the University of Cambridge in the group of Dr Ben Luisi. In September 2007 he was appointed as a lecturer at the University of Essex and continues to research into metalloenzymes and proteins.

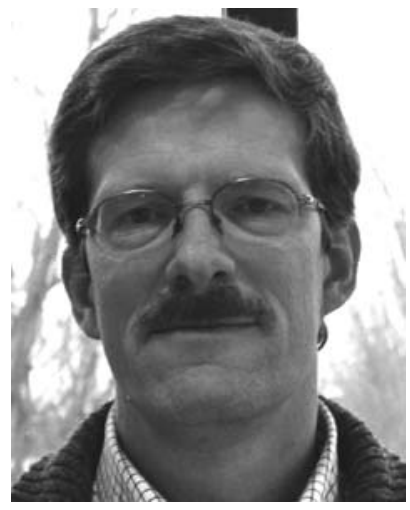

Erik Vijgenboom
Erik Vijgenboom obtained his PhD in 1989 (cum laude) in the group of Prof. Leendert Bosch (Leiden University, The Netherlands). The ins-and-outs of Streptomyces genetics and morphological development were learned as a senior EU Fellow in the group of Prof. Keith Chater in the John Innes Centre (UK). Upon his return to Leiden University he worked for several years in the group of Prof. Gerard Canters studying metalloproteins and copper homeostasis in Pseudomonas aeruginosa and Streptomyces. Since 2006 he has worked together with Prof. Gilles van Wezel on morphological development and the improvement of enzyme expression and secretion in Streptomyces. 


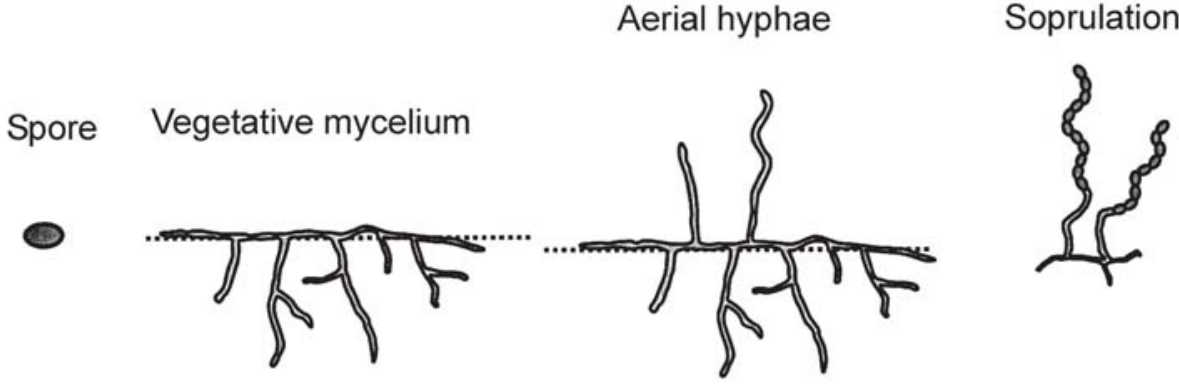

B
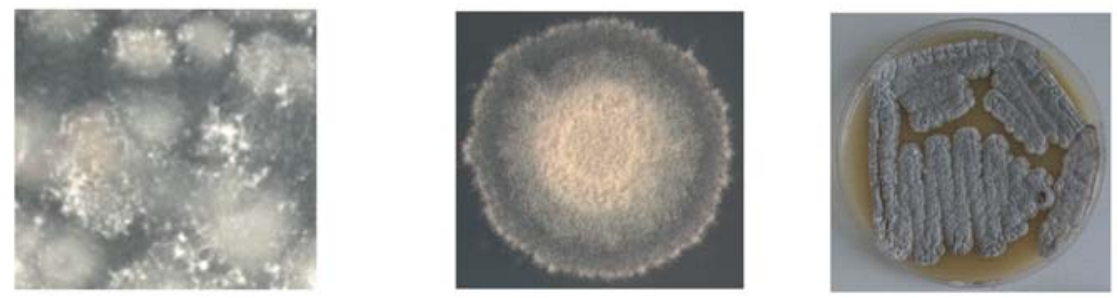

C
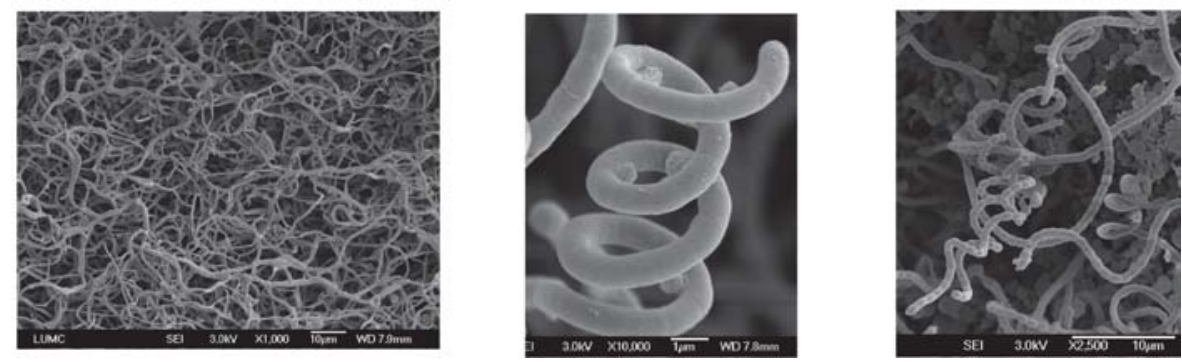

Fig. 1 A) The life cycle of Streptomyces from spore to spore. Upon germination of a spore two or more germ tubes are produced which grow out in a dense branched network of vegetative mycelium. When nutrients become limiting, an aerial mycelium is erected that feeds on the vegetative mycelium. Following the typical curling of the aerial hyphae, cell division takes place with cross-walls formed at regular distances. These compartments finally maturate into spores that can restart the cycle. B) The left panel shows colonies of vegetative mycelium that are on the brink of producing an aerial mycelium, illustrated by the patches of white fluffy aerial hyphae. A colony in full development of an aerial mycelium is shown in the middle panel, and complete sporulation with the typical grey spore pigment is visible in the right panel. C) Cryo-SEM pictures of the three developmental phases of Streptomyces, vegetative mycelium (left panel), coiled aerial hyphae (middle panel) and spore chains (right panel). The cryo-SEM pictures were kindly provided by J. Willemse and G. P van Wezel (MBT, LIC Leiden University, The Netherlands).

the role of zinc through the zinc-responsive regulator Zur and absC..$^{24,25}$

Why these microbes produce secondary metabolites has been a matter of some debate over the years. Having compounds around with antibacterial or antifungal activity during the part of the life cycle that switches from vegetative to aerial growth, when vulnerable to attack by other organisms does make sense. However, recently another argument has been put forward that sheds new light on this issue. ${ }^{26}$ Davies and coworkers ${ }^{26}$ suggest that these bioactive compounds in fact are signaling molecules. The effect of phenazine on colony morphology in Pseudomonas aeruginosa and that of actinorhodin and undecyl prodigiosin on the morphology of $S$. coelicolor lends support to this hypothesis. $^{27}$

\section{Other developmental factors}

The evidence that secreted molecules and proteins are of importance for the onset of development and secondary metabolite production is accumulating. The best known example is the bacterial hormone A-factor (2-isocapryloyl-3R-hydroxymethyl$\gamma$-butyrolactone) that was first identified in $S$. griseus, where it controls both secondary metabolism and development. ${ }^{28}$ Several butyrolactone autoregulators were purified from $S$. coelicolor. ${ }^{29}$ However, these factors do seem to control only secondary metabolism. Another example of a secreted substance that somehow has control over development is Factor C from $S$. falvofungini. ${ }^{30}$ Factor $\mathrm{C}$ has been shown to be a protein of 34.5 $\mathrm{kDa}$, which, when expressed in a bald, A-factor-deficient mutant of $S$. griseus, restores both development (aerial mycelium and spores) and A-factor production. ${ }^{31}$

\section{Redox versus morphogenesis}

The redox balance in the mycelium and the redox state of the environment seems to be important for developmental processes. This is exemplified by the fact that reducing sugars as carbon source, such as glucose, in general support good growth but are less suited for obtaining full development/sporulation. However, non-reducing carbon sources such as mannitol do allow for good sporulation. Data supporting a significant role for redox control in morphogenesis has started to accumulate. Several redox sensors have been identified in $S$. coelicolor. Rex is a sensor of the $\mathrm{NADH} / \mathrm{NAD}^{+}$redox poise and shown to induce the cytochrome 
$b d$ terminal oxidase operon upon oxygen limitation or inhibition of respiration through the cytochrome $c$ oxidase. ${ }^{32}$ The rex null mutant grew poorly and had a delayed development. Another example is the sigma factor $\sigma^{\mathrm{R}}$ that is involved in transcription regulation in response to disulfide stress. However, the mutant of this thiol-based regulatory switch does not seem to be affected in growth, development and secondary metabolism. ${ }^{33}$

The family of Wbl proteins, of which the S. coelicolor WhiB is the founding member and one of the best characterized, is also implemented in redox sensing. The Wbl proteins have only been detected in actinomycetes and have been shown to play critical roles in the biology of both Streptomyces and Mycobacterium. ${ }^{34,35}$ WhiB of $S$. coelicolor is directly involved in morphogenesis because it was isolated as a mutant that does not produce spores. ${ }^{34}$ All members of the Wbl family are small proteins with many charged residues and four highly conserved cysteines. In the case of the WhiB-like protein, WhiD, it has been demonstrated that these cysteines can coordinate a $[4 \mathrm{Fe}-4 \mathrm{~S}]$ cluster ${ }^{36}$ and that this cluster plays a key role in redox sensing. The biochemical function, however, is a matter of controversy and debate. Wbl proteins were first suggested to function as transcriptional regulators, but were later shown to have disulfide reductase activity. ${ }^{37,38}$ However, a recent study with WhiD from S. coelicolor could not demonstrate disulfide reductase activity. ${ }^{39}$

\section{Copper and morphogenesis}

The transition metal copper has been shown to be of crucial importance for morphological development in Streptomyces. ${ }^{40,41}$ The copper dependence is restricted to the reproductive growth phase (aerial mycelium and spores) while vegetative growth proceeds even under strongly limited Cu-bioavailability ${ }^{41}$ (Fig. 2). Mutants defective in the Tat (twin-arginine translocation) secretory pathway do not or very slowly produce an aerial mycelium. ${ }^{42}$ Tat substrates are proteins that are secreted in a folded state and in general have a co-factor such as metal ions. The large number of putative Tat substrates in Streptomyces, 145-189, suggests that it is used as a general translocation pathway rather than a specific pathway for cofactor-containing enzymes. ${ }^{43}$ Development in the tat mutants can be restored by elevated copper levels. This evidence strongly suggests that copper proteins are among the secreted proteins/enzymes needed for development in Streptomyces.

The need for copper ions during morphogenesis is not restricted to streptomycetes. The GRISEA mutant of the filamentous fungus Podospora anserina has a diminished production of aerial hyphae and an extended life span. A reversion of this phenotype to wild-type characteristics is obtained upon addition of extra copper salts to the medium. ${ }^{44}$ The mutation in GRISEA turned out to be located in the gene for an orthologue of the copper-dependent Mac1 transcription factor of Saccharomyces cerevisae. ${ }^{45}$

\section{Copper proteins and enzymes in biology}

Copper can exist in either the $\mathrm{Cu}(\mathrm{I})$ or $\mathrm{Cu}(\mathrm{II})$ oxidation states and therefore has oxidative potential, which makes copper an essential element in proteins involved in electron-transfer chemistry and in the catalytic oxidation of various substrates in
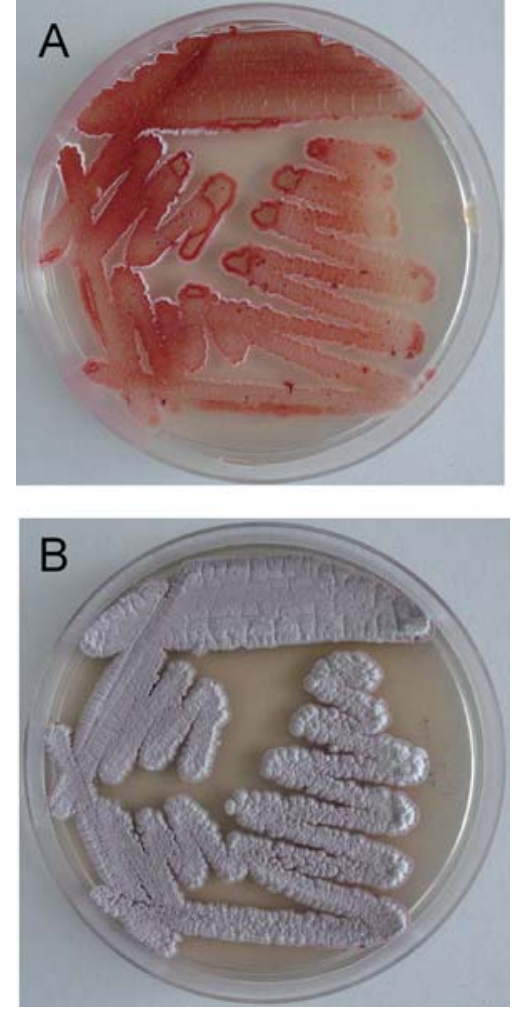

Fig. 2 Morphological development of Streptomyces lividans is completely dependent on the bioavailability of copper ions. A) On R5 medium (a complex medium containing yeast extract and glucose as carbon source) with the addition of the $\mathrm{Cu}$-specific chelator BCDA (bathocuproin disulfonic acid) development is arrested in the vegetative growth phase. B) On regular R5 medium, containing about $0.2 \mu \mathrm{M} \mathrm{Cu}^{1+1}$ ${ }^{2+}$, development proceeds all the way up to the production of spores that have the typical grey color of the pigment produced during this phase of development.

both eukaryotic and prokaryotic organisms. The myriad functions of copper proteins/enzymes are in part dictated by the coordination geometry of the active site copper ion(s), with different amino-acid binding motifs often representative of the class and function of the protein. Historically, copper sites in proteins have been grouped into three classes based on the electronic structure and geometry of the copper site; Type 1 (blue), Type 2, and Type 3 (coupled binuclear). ${ }^{46}$ With the advent of whole-genome sequencing coupled to structural proteomics, the discovery of new cupric and cuprous binding motifs in proteins has expanded the original classification. Currently, there are seven different types of redox active copper sites found in biology. These all have characteristic ligand geometries, spectroscopic properties and varying cellular functions. The copper active-site geometries relevant to some of the copper proteins identified in Streptomyces are depicted in Fig. 3.

Copper, as with other cellular transition metal ions, poses a threat to the cell in excess. Reduced copper has to be kept under control, such as is done in a protein environment, as otherwise it is highly reactive, catalyzing the production of hydroxyl radicals that can damage the genetic, enzymatic and structural components of the cell. This deleterious behavior results in bacteria having a low cytosolic copper requirement. ${ }^{47}$ Fluctuations in the 


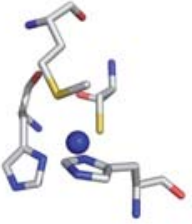

Type 1

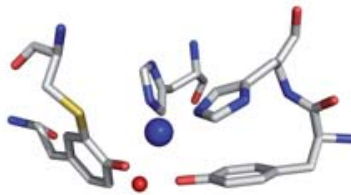

Type 2

B

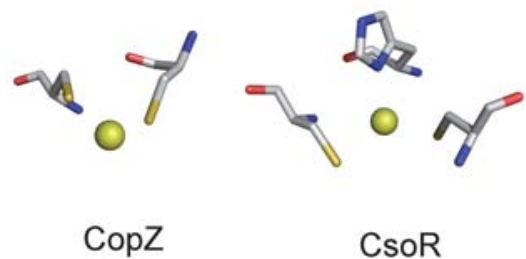

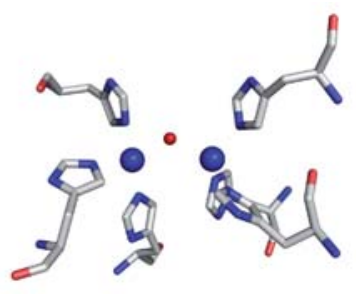

Type 3

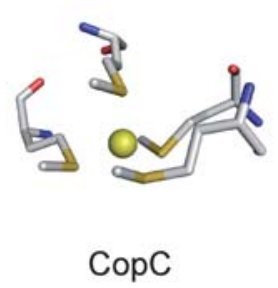

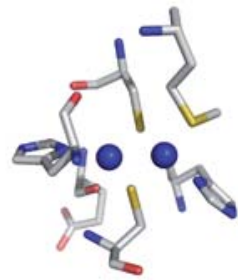

$\mathrm{Cu}_{\mathrm{A}}$

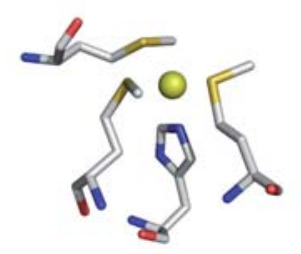

DR1885

Fig. 3 A selection of copper active sites commonly found in biology. A) Redox active copper sites. In the Type 1 site the copper ion is coordinated in a distorted tetrahedral geometry by two His residues, a Cys thiolate and a weakly coordinating axial Met thioether. In a Type 2 site a mononuclear copper ion is coordinated by $\mathrm{N}$ and/or $\mathrm{O}$ ligands arranged in a square planar geometry with a vacant coordination site for a substrate molecule or water coordination (depicted as a red sphere). In the binuclear Type 3 site each copper is coordinated through three His ligands in a trigonal pyramidal geometry. This geometry can change upon the coordination of a bridging ligand (red sphere) to distorted tetragonal. The binuclear $\mathrm{Cu}_{\mathrm{A}}$ site has two $\mathrm{Cys}_{\mathrm{S}}$ thiolates bridging the copper ions and further coordination from two His residues, a Met and an oxygen of a backbone carbonyl. B) Chaperone and sensor copper sites. CopZ has bis-Cys geometry commonly associated with binding $\mathrm{Cu}(\mathrm{I})$. Cso $\mathrm{R}$ coordinates $\mathrm{Cu}(\mathrm{I})$ in a trigonal geometry provided by two Cys thiolates and a His residue. CopC (at pH 4.5) and DR 1885 both coordinate $\mathrm{Cu}(\mathrm{I})$ in a tetrahedral geometry, utilizing the thioether chemistry of Met. The Met ligand coordination monopoly is broken in DR1885 by a His residue. At pH7.5 CopC swaps a coordinating Met for a His, resulting in a coordination sphere identical to that of DR1885. ${ }^{129}$

availability of cytsolic $\mathrm{Cu}(\mathrm{I})$ in the cell is safeguarded by proteins that bind the potentially deleterious cuprous ion and prevent redox chemistry from occurring. ${ }^{48-54}$ Proteins specific for $\mathrm{Cu}(\mathrm{I})$ have coordination chemistries that are quite distinct from those seen in canonical redox active copper proteins and enzymes (Fig. 3B). Cuprous ions are thiophilic and have a high affinity for bis-cysteine coordination. In eukaryotes, copper-specific regulators and chaperones have been identified in the strongly reducing environment of the cytoplasm or in the reducing environment of intracellular compartments. These proteins have as a minimum pre-requisite to sequester and transport $\mathrm{Cu}(\mathrm{I})$, a $\mathrm{CX}_{\mathrm{n}} \mathrm{C}$ motif. ${ }^{50,55}$ In bacteria the major copper trafficking routes are in the less reducing extracellular (Streptomyces and Bacillus subtilis) or periplasmic (Escherichia coli) environment. ${ }^{47,56,57}$ The Cys thiolate chemistry commonly observed for eukaryotic cytosolic $\mathrm{Cu}(\mathrm{I})$ chaperones is still used (e.g. bacterial Sco1) but it is noted that a number of bacterial chaperones bind $\mathrm{Cu}(\mathrm{I})$ through thioether sulfur coordination arising from methionine residues. The thioether group lacks the electrostatic component of a Cys thiolate and therefore imparts a weaker affinity for $\mathrm{Cu}(\mathrm{I})$. As a consequence of this decreased affinity a higher coordination number is often observed (Fig. 3B). ${ }^{58}$

\section{A blue-print of copper proteins in $S$. coelicolor}

Knowledge of the various copper binding motifs in biology enables in silico mining of genome databases to identify putative copper proteins/enzymes. ${ }^{59}$ This can subsequently lead to the identification of the type of systems used by an organism for copper homeostasis and also provide information as to the type of enzymatic reactions carried out by the organism which are unique to copper enzymes. Sequencing of the $S$. coelicolor genome has been completed and is considered as a model organism for the study of Streptomyces development and secondary metabolite production. ${ }^{60}$ An inventory of putative copper proteins/enzymes in the $S$. coelicolor genomic database has been undertaken using an analysis of common copperbinding or copper-associated amino acid motifs and on the basis of overall protein similarity followed by searching for copperbinding sequences 'by eye'. The blue-print of copper proteins produced is similar to that reported by Andreini et al. ${ }^{59}$ Table 1 summarizes the genes found in $S$. coelicolor that putatively encode for a protein or enzyme involved in either binding or transporting copper. It should be noted, however, that this inventory is not definitive and that in other Streptomyces genomes copper proteins may vary. There are also a number of genes which although identified as containing a known copper binding motif, it is not as apparent as it is for others, if they are truly copper proteins e.g. SCO7671 (Table 1).

Using bioinformatics tools to detect export signal peptides and transmembrane regions, the potential location for a number of putative copper proteins reported in Table 1 have been identified (Fig. 4). It is noted that a number of the extracellular putative copper proteins are predicted to be lipoproteins, where the $\mathrm{N}$-terminal Cys residue at the +1 position is modified to form a thioether linkage to a diglyceride of a lipid ${ }^{61-64}$ (Fig. 4). Despite this anchorage point, these proteins are known to move location within the extracellular environment. Of the predicted copper proteins in $S$. coelicolor and/or their orthologues in other Streptomyces species, a number have been subjected to protein 
Table 1 The genes identified in S. coelicolor that putatively encode for copper-containing proteins or enzymes.

\begin{tabular}{|c|c|c|c|c|c|}
\hline Classification & $\mathrm{SCO} \#$ & Description of gene product & $\begin{array}{l}\text { Predicted } \\
\text { localisation }^{c}\end{array}$ & $\begin{array}{l}\text { Translocation } \\
\text { pathway }\end{array}$ & References \\
\hline \multirow[t]{5}{*}{ Enzymes } & 2700 & Tyrosinase (melD2) $^{a}$ & $\mathrm{C}$ & - & 82 \\
\hline & 3439 & A two-subunit multicopper oxidase & $\mathrm{S}$ & Tat & - \\
\hline & 3440 & A two-subunit multicopper oxidase & $\mathrm{S}^{b}$ & - & - \\
\hline & 6710 & Glycosyl hydrolase with a putative Type $1 \mathrm{Cu}$ site & $\mathrm{S}$ & Sec & - \\
\hline & 6712 & A small two-domain laccase; SLAC & $\mathrm{S}$ & Tat & 84 \\
\hline \multirow[t]{3}{*}{ Electron transport } & 2155 & Cytochrome c oxidase subunit $\mathrm{I}, \mathrm{Cu}_{\mathrm{B}}$ centre & M & - & - \\
\hline & 2156 & Cytochrome $\mathrm{c}$ oxidase subunit II, $\mathrm{Cu}_{\mathrm{A}}$ centre & M & $\mathrm{Sec}$ & - \\
\hline & 7674 & A high potential cupredoxin; lipocyanin & M, lipo & $\mathrm{Sec}$ & 61 \\
\hline \multirow[t]{4}{*}{ Chaperones } & 1045 & CopZ-like $\mathrm{Cu}$ chaperone & $\mathrm{C}$ & - & - \\
\hline & 2701 & A tyrosinase chaperone (melD1) & $\mathrm{C}$ & - & 82 \\
\hline & 2730 & CopZ-like $\mathrm{Cu}$ chaperone & $\mathrm{C}$ & - & - \\
\hline & 3965 & An orthologue of DR $1885\left(\mathrm{Cu}_{\mathrm{A}}\right.$ assembly $)$ & M, lipo & $\mathrm{Sec}$ & - \\
\hline \multirow{5}{*}{ Metal transport and storage } & 2731 & P-type ATPase, with SCO2730 the $\mathrm{Cu}$ chaperone & M & - & - \\
\hline & 3964 & A putative $\mathrm{Cu}$ transporter & M & $\mathrm{Sec}$ & - \\
\hline & 4053 & Similar to 3964; CopC/D similarity/domains/signatures & M & $\mathrm{Sec}$ & - \\
\hline & 4315 & CutC-like (Cu transporter in E. coli) & $\mathrm{C}$ & - & - \\
\hline & 6117 & CutC-like (Cu transported in E. coli) & $\mathrm{C}$ & - & - \\
\hline Transcription regulation & 4136 & $\mathrm{~A} \mathrm{Cu}$-responsive transcriptional regulator, $\mathrm{Cso} / \mathrm{RcnR}$ family & $\mathrm{C}$ & - & - \\
\hline
\end{tabular}

${ }^{a}$ The melD2 homolog, melC2, is a secreted protein and Tat pathway substrate. ${ }^{b} 3440$ does not have a signal sequence but is predicted to be secreted together with 3439. ${ }^{c}$ Localization: C(ytoplasm); M(embrane); S(ecreted); Lipo(protein). Protein localization and translocation is predicted with the SignalP, TatP, LipoP and TMHMM servers. ${ }^{131}$

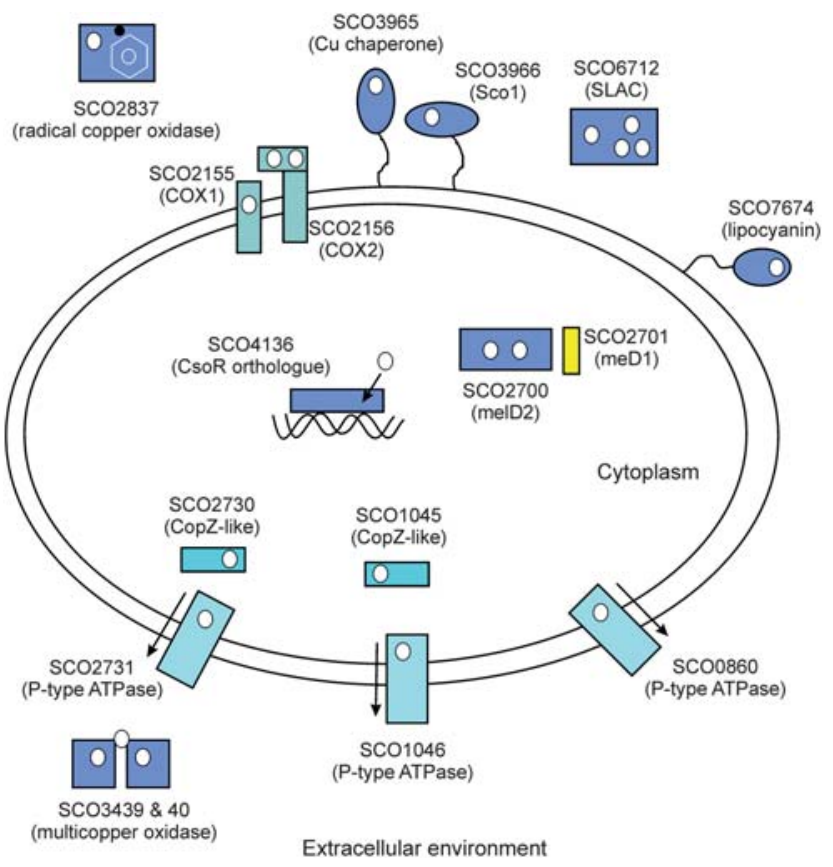

Fig. 4 A cellular overview of copper proteins, enzymes and transporters found in the cytoplasm and extracellular environment of $S$. coelicolor. The cellular locations are predicted on the basis of membrane-spanning domains or $\mathrm{N}$-terminal signal sequences. Lipoproteins are shown as being tethered to the membrane. Other putative proteins/enzymes with copperbinding motifs have also been identified (Table 1) but are omitted from this cartoon. chemistry studies. These have afforded insight into the enzymology, active-site structure and chemistry, and in a handful of cases tertiary structural information is available through X-ray crystallographic studies. Coupled with some in vivo and proteomics data, snapshots of the role copper and its proteins play in Streptomyces development and secondary metabolite production is beginning to emerge.

\section{Copper enzymes and secondary metabolite production}

\subsection{A multicopper oxidase with phenoxazinone synthase activity}

The phenoxazinone chromophore has been found in various biological systems and forms the core structure of certain antibiotics (Fig. 5A). The class of enzyme responsible for the biosynthesis of phenoxazinone is a 2-amino-phenol:oxygen oxidoreductase or more commonly referred to as phenoxazinone synthase (PHS) (for a recent review of PHS see ref. 65). A PHS was first discovered in $S$. antibioticus and for some time was believed to be essential in the biosynthesis of the phenoxazinonecontaining antibiotic actinomycin, which is a potent anticancer agent. However, it has been shown that actinomycin production is still present in a $S$. antibioticus strain lacking PHS activity. ${ }^{66}$ The PHS in $S$. antibioticus was identified as being a copper protein with high sequence similarity to laccases and was therefore classed as a member of the multicopper oxidase family of proteins. This has been subsequently confirmed through 
A

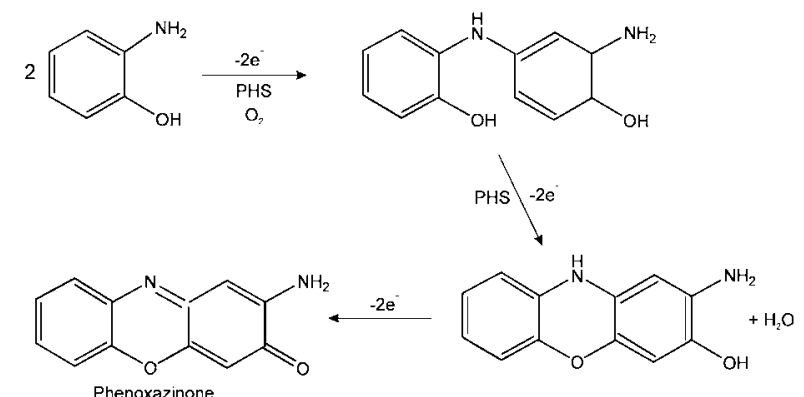

B

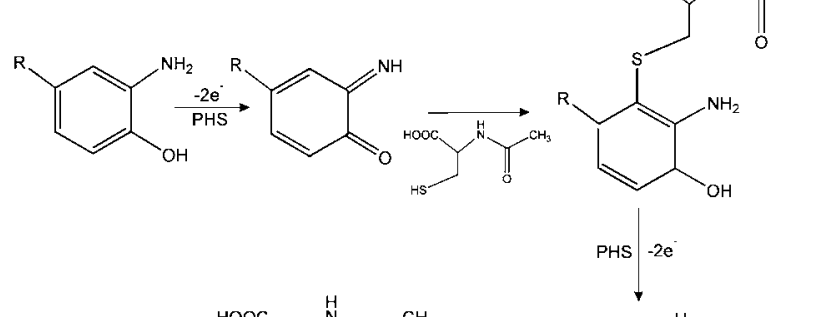

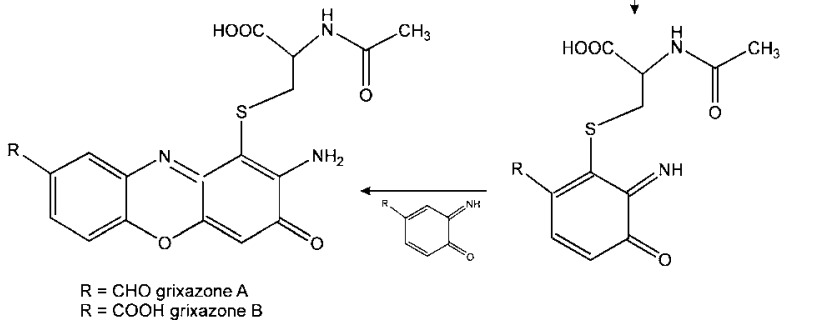

Fig. 5 The biosynthetic pathway for the production of the phenoxazinone chromophore. A) The reaction catalyzed by the multicopper oxidase PHS from $S$. antibioticus involves two two-electron oxidations with the concomitant reduction of dioxygen to water and a final twoelectron oxidation to yield the phenoxazinone chromophore. B) The reaction catalyzed by GriF, the tyrosinase-like PHS, from S. griseus. 3-Amino-4-hydroxybenzaldehyde is oxidized by GriF to the corresponding quinone-imine followed by the non-enzymatic conjugation of the $-\mathrm{SH}$ group of $N$-acetylcysteine. This compound undergoes subsequent two-electron oxidation by GriF to its quinone-imine, followed by non-enzymatic coupling with a second molecule of a quinone-imine to form the phenoxazinone product, grixazone.

structure determination by X-ray crystallography. ${ }^{67}$ The reaction catalyzed by the PHS from $S$. antibioticus is an oxidative condensation of two $o$-aminophenols to yield the 2-aminophenoxazinone product (Fig. 5A). The oxidative coupling of the 2-amino-phenol is thought to take place by a series of three twoelectron oxidations with the first two occurring enzymatically, and the last proposed to occur non-enzymatically. ${ }^{68}$ This type of reaction is unique among multicopper oxidase members, which normally carry out single-electron oxidation reactions. ${ }^{69}$

Two distinct oligomeric forms of PHS have been identified in S. antibioticus; a dimer and a hexamer. ${ }^{70}$ The cellular location of these two forms of PHS is not entirely clear. From our sequence analysis no export signal is present which would suggest that PHS is an extracellular protein. However, the occurrence of a copper enzyme in the cytosolic environment of most bacteria is unprecedented (see section 9.2). Nevertheless, it is the hexamer form of PHS which is most active towards substrate, ${ }^{\mathbf{7 0 , 7 1}}$ and it is the structure of this form which has been determined by X-ray crystallography. The structure reveals that each monomer

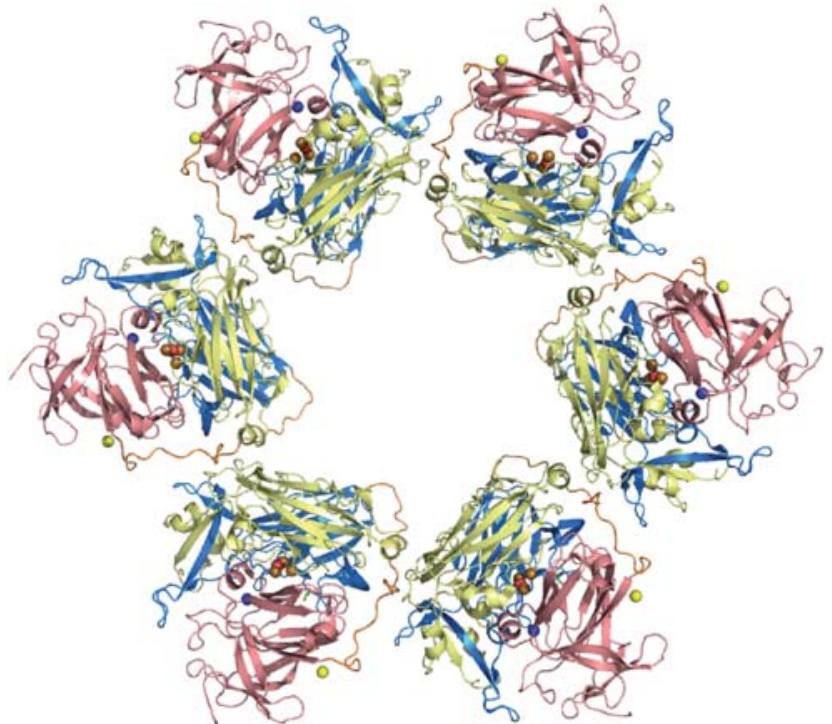

Fig. 6 The X-ray structure of the active hexamer of the multicopper PHS from $S$. antibioticus (pdb entry 2G23). ${ }^{67}$ Each monomer of the hexamer consists of three domains (domain 1 yellow; domain 2 blue; domain 3 pink). The Type 1 copper site (blue sphere) is located in domain 1 and the trinuclear cluster (brown) is located between domains 1 and 3 . Domains 2 and 3 are connected by a long loop (orange) which is structurally supported by a copper ion (yellow sphere) coordinated by three His residues.

consists of three Greek key $\beta$-barrel or cupredoxin domains architecturally arranged in a manner that resembles other multicopper oxidases. ${ }^{67}$ The hexameric ring structure is centered on a pseudo-six-fold axis and has a large central cavity of $50 \AA$ (Fig. 6). A Type 1 copper site is found in domain 1 with a trinuclear copper site or Type 4 site (Fig. 3A) located between domains 1 and 3, where the reduction of oxygen to water occurs. A unique feature of this particular multicopper oxidase is the presence of a fifth copper ion (multicopper oxidases normally have four copper ions). This is located some $25 \AA$ from the Type 1 and trinuclear copper sites ${ }^{67}$ (Fig. 6). The copper coordination sphere consists of three His residues arranged in a T-shape-like geometry with a vacant coordination site. Spectroscopic properties are consistent with it being a Type 2 copper site. A noncatalytic role for this fifth copper ion is proposed, and it is speculated to confer stability to a long loop that connects two domains which in turn helps to maintain and stabilize the active hexamer structure. ${ }^{67}$ Presumably, loss of this copper ion will therefore coincide with reduced enzymatic activity. Multicopper oxidases have been identified in the extracellular environment of $S$. coelicolor (vide infra) but these do not have homology to the multicopper PHS identified in S. antibioticus.

\subsection{Tyrosinase and a tyrosinase-like protein with phenoxazinone synthase activity}

In many Streptomyces species the tyrosinase gene (melC2) is part of the bicistronic melC operon. ${ }^{72}$ This operon also contains an ORF called melCl which encodes a histidine-rich protein that acts as a multi-purpose chaperone, delivering copper to apotyrosinase and directing its secretion to the extracellular 


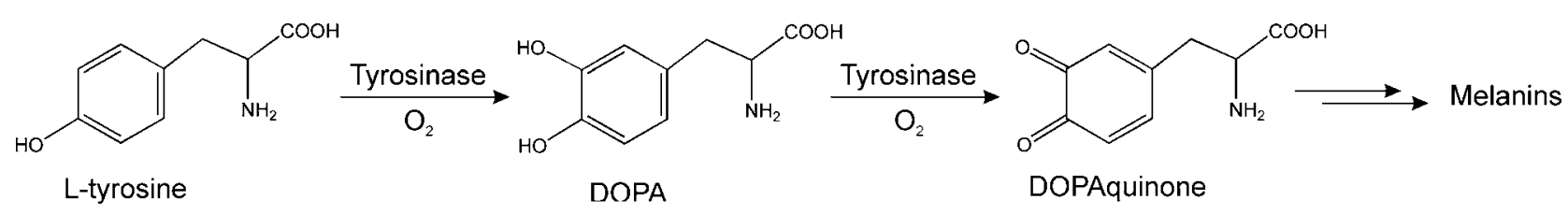

Fig. 7 The initial catalytic steps of the Raper-Mason melanogenesis pathway require the copper enzyme tyrosinase. Hydroxylation of L-tyrosine to L-3,4-dihydroxyphenylalanine (DOPA) is followed by oxidation to 4-(2-carboxy-2-aminoethyl)-1,2-benzoquinone (DOPAquinone), a reactive precursor to melanin production.

environment. ${ }^{73-75}$ Tyrosinase contains a Type 3 copper site (Fig. 3A) and is the key enzyme in the melanogenesis pathway, producing melanins in bacteria to humans. Melanins are heterogeneous light-absorbing polyphenolic polymers with colors ranging from yellow to black derived from the oxidation of tyrosine. ${ }^{76}$ Melanogenesis fulfils a number of physiological roles in different organisms, ranging from spore formation in fungi to the photo-protection of skin from UV light in humans. ${ }^{77-81}$ In the melanogenesis pathway, the extracellular tyrosinase is activated by oxygen and catalyses the hydroxylation of L-tyrosine to DOPA followed by oxidation to DOPAquinone with concomitant reduction of oxygen to water ${ }^{69}$ (Fig. 7). DOPAquinone is then converted by a series of enzymatic and spontaneous conversions to produce the various melanins.

As the completed genome sequences for various Streptomyces species become available, a bicistronic operon homologous to melC has been found in all the sequenced chromosomes, and has subsequently been named melD. ${ }^{82}$ The melD operon also contains melD1 which is homologous to the melC2 gene encoding for the chaperone protein (Fig. 4). In contrast to melC2, melD2 is not secreted to the extracellular environment and is therefore unlikely to be involved in melanin biosynthesis. In $S$. coelicolor the lack of melanin production was initially thought to be due to an inactive tyrosinase gene (SCO2700). However, our current understanding is that the tyrosinase gene identified in $S$. coelicolor is part of the melD operon and is therefore not secreted. ${ }^{\mathbf{2}}$ melD2 exhibits monophenol and diphenol oxidase activities typical of an extracellular tyrosinase ${ }^{82}$ and this therefore suggests that melD2 is an example of a cytoplasmic copper enzyme. The occurrence of cytosolic copper enzyme in a Gram-positive bacterium would be unique, as a metabolic requirement for copper to cross the plasma membrane into the cytoplasm has not been documented ${ }^{47}$ Further molecular and genetic studies with melD2 to probe its copper dependence are therefore required. The present hypothesis for the function of melD2 in Streptomyces is based on studies using genetic knockouts and activity assays, and alludes to a role in protecting the cell from damage by common plant phenolic compounds by interfering with the spontaneous ROS-generating quinone-hydroquinone redox cycle. $^{82}$

The Streptomyces species $S$. griseus possesses both the melC and melD operons, and in addition has another pair of melCl and melC2 homologues ( $\mathrm{rriE}$ and girF). These genes are embedded in the grixazone biosynthesis gene cluster, consisting of 13 genes whose transcriptional activator is under the control of the A-factor (see section 4) and phosphate depletion. ${ }^{28}$ Grixazone is a secondary metabolite produced by $S$. griseus, which possesses a phenoxazinone chromophore and contains a mixture of grixazone $\mathrm{A}$ and $\mathrm{B}$, with the latter having parasiticide activity $^{83}$ (Fig. 5B). Deletion of the griEF locus on the chromosome of $S$. griseus resulted in no production of grixazone but instead led to the accumulation of 3-amino-4-hydroxybenzaldehyde (3,4-AHBAL) and its acetylated compound ${ }^{83}$ (Fig. 5B). GriE and GriF display 50\% sequence identity to $\mathrm{MelC1}$ and $\mathrm{MelC2}$, respectively. The Type 3 copper binding motif has been identified in GriF, and GriE has been shown to activate GriF activity through the transfer of two copper ions to assemble the Type 3 catalytic site. ${ }^{83}$ Unlike true tyrosinases however, GriF is unable to carry out monophenolase reactions, but has unique substrate specificities for $o$-aminophenols to yield an $o$-quinone-imine derivative, which is then non-enzymatically coupled with another molecule of $o$-quinone-imine to form the phenoxazinone-containing grixazone ${ }^{83}$ (Fig. 5B). Thus, despite quite clear difference in structure and genetic makeup compared to the multicopper oxidase PHS from S. antibioticus, GriF can also be termed a PHS. Both these copper enzymes are therefore potential candidates for biotransformation for use in robust Streptomyces expression strains for the production of novel phenoxazinone antibiotics. ${ }^{65}$

\section{Characterizing copper proteins and enzymes from S. coelicolor}

From in silico mining of the completed $S$. coelicolor genome, a number of proteins and enzymes have been predicted to require copper for function (Table 1). To test the in silico predictions a handful of the corresponding genes have been subjected to recombinant over-expression in host bacterial systems. This has enabled the purified proteins to be subjected to structural and mechanistic studies, affording insight into some novel features not commonly associated with homologues in other bacteria.

\subsection{Small laccase (SCO6712)}

Multicopper oxidases, of which laccases are members, oxidise a variety of organic and inorganic substrates by molecular oxygen. Reducing equivalents are accepted by the Type 1 copper site and transferred to a trinuclear cluster, where oxygen is reduced to water (Fig. 3A and 8). Structural information on multicopper oxidases is available and reveals these multi-domain proteins to consist of three cupredoxin-type domains (Fig. 8). Domain 1 contains the Type 1 copper site and the trinuclear cluster is located at the interface of domains 1 and 3 (Fig. 8). Domain 2 connects the other two domains and helps to shape the access and exit channels to the trinuclear cluster. In S. coelicolor, SCO6712, was predicted to encode for a multicopper oxidase, based on the conserved copper binding motifs identified in the amino-acid sequence. However, sequence alignments with other 


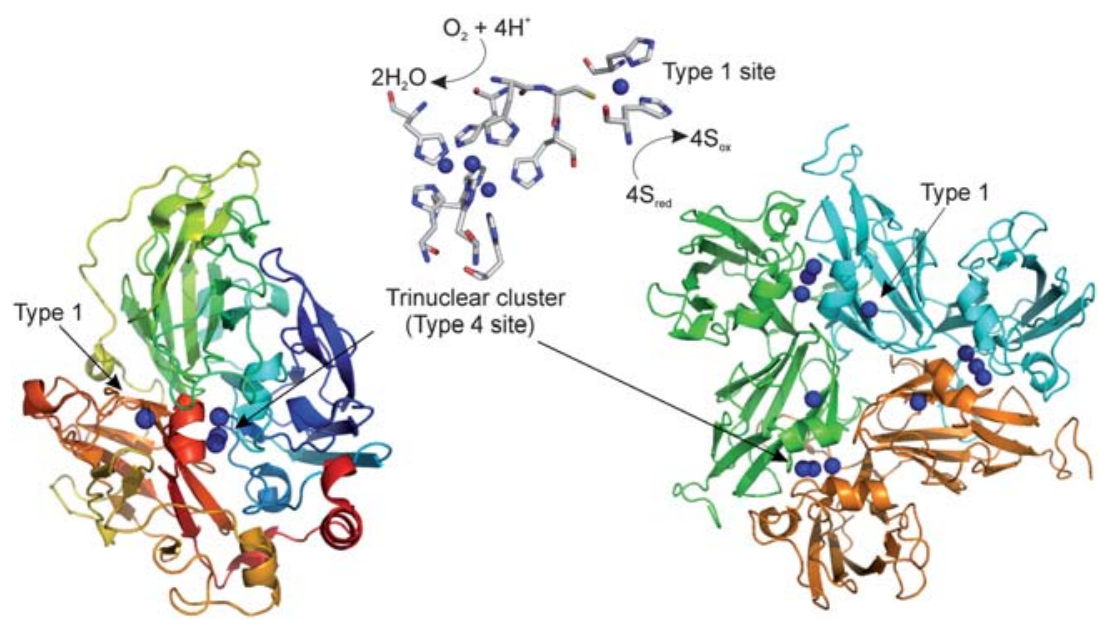

Fig. 8 Multicopper oxidases. The active site structure of a multicopper oxidase is shown in sticks, with the blue spheres indicating the four copper atoms. The reduced substrate binds close to the Type 1 copper site and the reducing equivalents are passed to the trinuclear cluster for the reduction of oxygen. The three domain structure of laccase from Trametes versicolor is shown to the left of the active site (pdb entry $1 \mathrm{GYC}) .{ }^{130}$ The three cupredoxin domains are colored differently and arranged in a manner such that the trinuclear cluster is interfaced between domains 1 and 3 . To the right of the active site is the X-ray structure of SLAC viewed along the approximate 3-fold axis of the trimer (pdb entry $3 \mathrm{CG} 8$ ), ${ }^{85}$ which forms the channel leading to the central cavity of the protein and subsequent access to the trinuclear cluster. Each monomer is colored differently, and the blue spheres represent the copper sites.

multicopper oxidases e.g. laccases, revealed that $\mathrm{P} 6712$ (P denotes the protein encoded by SCO6712) lacked domain 2, making it roughly half the size of 'conventional' multicopper oxidases (343 vs. $\sim 600$ amino-acids). Machczynski et al. ${ }^{84}$ heterologously expressed SCO6712 in E. coli and found that the purified protein existed in solution as a dimer with four copper ions per monomer. Spectroscopic evidence suggested that the four copper ions are arranged into the canonical Type 1 and trinuclear sites commonly associated with laccases.$^{84}$ The dimer form of the protein displays activity against a wide range of phenolic substrates as well as with negatively charged nonphenolic substrates. The activity with phenolic substrates reaches an optimum at alkaline $\mathrm{pH}$, in contrast to many other multicopper oxidases where phenol oxidase activity is measured at acidic $\mathrm{pH} .{ }^{84}$ In the monomer form, no phenol oxidase activity was detected and disruption of the gene abrogates laccase activity with phenolic substrates in the growth media, ${ }^{84}$ strongly suggesting that P6712 is the primary extracellular laccase in S. coelicolor. P6712 therefore represents a new sub-class of the bacterial laccase-type enzymes and have been designated SLAC for Small LACcase. ${ }^{84}$

Following on from the initial spectroscopic characterization and activity assays, ${ }^{84}$ an X-ray structure of SLAC has been reported. ${ }^{85}$ Unlike the three domain laccases, the structure of SLAC is a trimer, with each monomer of the trimer consisting of two cupredoxin-like domains ${ }^{85}$ (Fig. 8). The trinuclear copper site is placed between domains 1 and 2 of each neighbouring chain of the trimer, and the Type 1 site is housed in domain $2^{85}$ (Fig. 8). In SLAC the coppers of the trinuclear cluster are coordinated through the $\mathrm{N} \varepsilon^{2}$ atoms of His residues, in contrast to the three-domain laccases where the $\mathrm{N} \delta^{1}$ atoms of the His residue provide the coordination. A large channel formed around the pseudo-3-fold axis of the trimer is openly accessible to solvent and leads to the central cavity of the protein (Fig. 8). Such an openly accessible solvent channel does not exist in the three domain laccases. A channel leading from the trinuclear site connects to this central channel and is considered as a possible entry and exit port for oxygen and water, respectively. The trimeric organization of the two domains leading to the formation of a central channel is very similar to the arrangement found in the trimeric copper enzyme nitrite reductase. ${ }^{86}$ Subsequently, SLAC reveals the highest structural homology with this family of copper proteins. This oligomeric state of SLAC found in the crystals is reported to be the active form when assayed against 2,6-dimethoxyphenol. ${ }^{85}$ Neither the dimer nor monomer forms were found to exhibit activity, and therefore contradicts the initial characterization of SLAC where the dimer from was reported to be the active species. ${ }^{84}$

On the opposite side to the channel lies a shallow, hydrophobic trimeric substrate-binding site ( $\sim 8 \AA$ in depth) in close proximity to the Type 1 sites. Currently, no ligand of SLAC resembling the trimeric character of the binding site is known. The substratebinding site is relatively small, and interactions with more than one protein chain are unavoidable even for small ligands. ${ }^{85}$ Defining the structural constraints for substrate binding is important for insight into substrate specificity, the unusual $\mathrm{pH}$ dependence of activity with phenolic substrates and for revealing the true role of this enzyme.

Mechanistically, the oxygen-to-water conversion in multicopper oxidases, and in particular laccases, has been extensively studied. ${ }^{69,87}$ The first step in the reduction of oxygen by a fourelectron-reduced laccase consists of two-electron oxidation of the Type 3 site with concomitant production of a peroxide intermediate, followed by a one-electron step whereby the oxygenoxygen bond is broken and an oxygen radical is produced. A recent mechanistic study of the enzymatic reduction of oxygen by SLAC has identified a transiently populated species in both the enzymatic turnover and single-turnover experiments that has been attributed to a protein radical intermediate ${ }^{88}$ arising from a $\mathrm{Cu}^{2+}$-tyrosyl radical formed at the Type 2 site of the trinuclear 
cluster. ${ }^{88}$ Based on spin-spin distances calculated from EPR measurements and analysis of the X-ray crystal structure of SLAC, Tyr108 at the end of the channel that leads to the trinuclear cluster is a strong candidate for the protein radical. ${ }^{\mathbf{8 5 , 8 8}}$ Such an intermediate has not been detected in three-domain laccases, and it remains to be seen if this is unique to SLAC or if it is also present in other members of the small laccase family.

Laccases have application as industrial catalysts. One drawback, however, is the difficulty in isolating functional glycosylated fungal laccases. SLAC displays resistance to detergents and has a high thermal stability, which coupled with its high $\mathrm{pH}$ activity optimum for phenolic substrates and its relative ease of isolation using bacterial host systems make it an attractive candidate for applied applications. ${ }^{84,89}$ In this respect SLAC has been patented by Novozymes, for among others, use in bleaching processes (Novozymes, Uses of laccase, World Pat. WO 2007/054034, 2007). A further active area of applied investigation is the employment of laccase-coated cathodes in biofuel cells. A recent report describing a SLAC-coated cathode revealed that the current density for enzymatic oxygen reduction at neutral $\mathrm{pH}$ outperforms that of other fungal laccases so far tested..$^{90}$

\subsection{Lipocyanin (SCO7674)}

SCO7674 is predicted to be involved in electron-transfer chemistry (Table 1). Over-expression of SCO7674 in E. coli, purification and subsequent UV-visible, EPR and NMR spectroscopies have confirmed the in silico prediction that P7674 is a cupredoxin possessing a Type 1 copper site with Met as the axial ligand ${ }^{61}$ (Fig. 3A). The N-terminal amino-acid sequence reveals characteristics of prokaryotic lipoproteins, ${ }^{61,62}$ with a Cys residue forming a thioether linkage to a diglyceride of a lipid. ${ }^{63,64}$ These findings, together with the spectroscopic confirmation of a Type 1 copper site, led to P7674 being named lipocyanin (lpc). ${ }^{61}$ Homology searches revealed lpc to have a high sequence identity to the amicyanin family of cupredoxins. These proteins function as redox carriers in Gram-negative bacteria, which rely on methylamine as an energy source. ${ }^{91}$ In particular, the copperbinding loop in lpc, which contains three of the four copper ligands, is the same length as in amicyanin. This copper-binding loop varies in size and sequence amongst members of the cupredoxin family, and a number of studies have focused on ascertaining the relative contributions of loop length, amino-acid sequence and structure in tuning the Type 1 active-site properties. ${ }^{92,93}$

One such property of a cupredoxin, and indeed other redox proteins, is the mid-point redox potential $\left(E_{\mathrm{m}}\right)$, which strongly regulates function. For amicyanin the $E_{\mathrm{m}}$ of the $\mathrm{Cu}(\mathrm{I}) / \mathrm{Cu}(\mathrm{II})$ couple is $+280 \mathrm{mV}$ ( $v s$. NHE) and is the lowest reported in the cupredoxin family with Met as the axial copper ligand.94,95 Nevertheless, this $E_{\mathrm{m}}$ is sufficient for amicyanin to transfer an electron to its substrate at a biologically optimal rate. For lpc the $E_{\mathrm{m}}$ has been reported to be $+605 \mathrm{mV}$ ( $v s$. NHE) and is so far the highest $E_{\mathrm{m}}$ for a cupredoxin possessing a 'classic' Type 1 copper site. ${ }^{61}$ In the absence of an X-ray structure, it is difficult to come up with a rationale for this elevated potential, although secondsphere coordination effects have been suggested as possible factors. ${ }^{61}$ A recent study with another cupredoxin (Azurin) has revealed the importance of second-sphere coordination properties for tuning the $E_{\mathrm{m}}$ beyond the natural range. ${ }^{96}$ Putative high-potential cupredoxins have also been identified in other actinobacteria but their functions remain unknown. ${ }^{61}$ In $S$. coelicolor the surrounding genomic environment of SCO7674 suggests that lpc could be involved in oxidation of a substrate prior to uptake and transport across the membrane by an $\mathrm{ABC}$ transporter. ${ }^{61}$

\subsection{A radical copper oxidase (SCO2837)}

SCO2837 encodes for a protein with weak sequence similarity to the fungal enzyme galactose oxidase. ${ }^{97}$ The latter is a member of the radical copper oxidase family, which participate in the twoelectron oxidation of an organic substrate and reduction of oxygen to hydrogen peroxide. ${ }^{97,98}$ The active site contains a copper ion and a catalytic motif based on a tyrosyl-cysteine thioether cross-link that forms a stable amino acid side-chain radical $^{99}$ (Fig. 3A). In S. coelicolor, SCO2837 occurs within a central core region of the genome with genes required for essential cellular functions in close proximity. SCO2837 appears to form a bicistronic operon with SCO2836, the latter encoding for a glycosyl transferase which is involved in hyphal tip growth and morphological differentiation. ${ }^{100} \mathrm{P} 2837$ is secreted to the growth medium of $S$. coelicolor cultures and is found to be primarily associated with the cell surface, similar to the fungal enzyme galactose oxidase. P2837 has recently been isolated in large enough quantities to ascertain preliminary biochemical data, ${ }^{101}$ which reveal the oxidized protein possesses a protein free radial, that upon one-electron reduction disappears, leaving an EPR spectrum of a typical mononuclear $\mathrm{Cu}$ (II) ion in a tetragonal ligand environment. A biologically relevant substrate is at present not known; however, kinetic assays demonstrate that the enzyme preferentially catalyzes oxidation of primary alcohols to aldehydes, but with quite distinct kinetic properties compared with the classical galactose oxidase. ${ }^{101}$ These observations represent the first characterized example of a prokaryotic radical copper oxidase. The production of $\mathrm{H}_{2} \mathrm{O}_{2}$ may provide a hint to its cellular function, with $\mathrm{H}_{2} \mathrm{O}_{2}$ known to play an important role in signaling and fueling extracellular peroxidases in Actinomycetales. ${ }^{102}$

\section{Copper trafficking and development}

Is has become increasingly well documented in both prokaryotic and eukaryotic organisms that the uptake and regulation of copper is a very tightly controlled process. The concentration of 'free' copper in bacteria is negligible, and helping to maintain this level are proteins that serve as $\mathrm{Cu}(\mathrm{I})$ chaperones and regulators. In $S$. coelicolor putative $\mathrm{Cu}(\mathrm{I})$ chaperones have been identified in both the extracelluar and cytosolic environment (Fig. 4). In addition a putative $\mathrm{Cu}(\mathrm{I})$ sensor protein, that in other bacterial organisms up-regulates a cytosolic $\mathrm{Cu}(\mathrm{I})$ efflux system in response to $\mathrm{Cu}$ (I) stress, has also been identified (Fig. 4). Despite knowing that copper plays a critical role in the development cycle of Streptomyces, detailed information is lacking on the molecular and genetic level regarding the trafficking and regulation of copper in these organisms. A summary of our current knowledge in this area is outlined in the following sections. 


\subsection{Tyrosinase and its copper chaperone}

The most well documented copper chaperone in Streptomyces biology is the tyrosinase-specific melC1. This chaperone is responsible for directing the secretion of tyrosinase (melC2) to the extracellular environment and for assembling the catalytic Type 3 copper site. ${ }^{75}$ Recent insight on the molecular level of copper ion transfer between a melC1-like protein and a tyrosinase has been revealed through X-ray crystal structure determination of the complex from $S$. castaneoglobisporus. ${ }^{103}$ The chaperone protein binds to a surface area of tryrosinase that would prevent access of substrate to the Type 3 site (Fig. 9). This suggests that assembly of the active site occurs prior to the maturation of other parts of the protein. The melC1-like protein has significant structural homology to the $\mathrm{SH} 2$ domain, which commonly occurs in proteins with a role in a cell signaling, such as tyrosine kinase. ${ }^{104}$ Prior to this complex structure, no atomic resolution information for tyrosinase was available, and the large body of mechanistic work on this enzyme had been interpreted through the use of homology models based on the X-ray structures of other Type 3 copper family members which display different substrate specificity. ${ }^{\mathbf{1 0 5 , 1 0 6}}$ The structure of tyrosinase revealed features that give rise to variation in substrate specificities amongst Type 3 family members and also inferred a high degree of flexibility within the Type 3 site during catalysis. ${ }^{103}$

Co-crystals of the complex between tyrosinase and its chaperone protein were subjected to different soaking times with cupric salts. ${ }^{103}$ Solving the structures of these crystals led to the identification of two copper binding sites on the surface of melC1 (Fig. 9). Residues coordinating the copper at the first site are not well defined due to disorder in the crystal. However, one residue observed to bind copper at this site is His82, which coordinates the copper through its side chain $\mathrm{N} \delta$ atom. From sequence analysis, other His residues are speculated to be involved in copper ion binding at the first site. By contrast, the second binding site on MelC1 is well resolved and also involves His82, but the copper is now coordinated through the $\mathrm{N} \varepsilon$ atom of its imidazole ring. The coordination sphere at the second binding

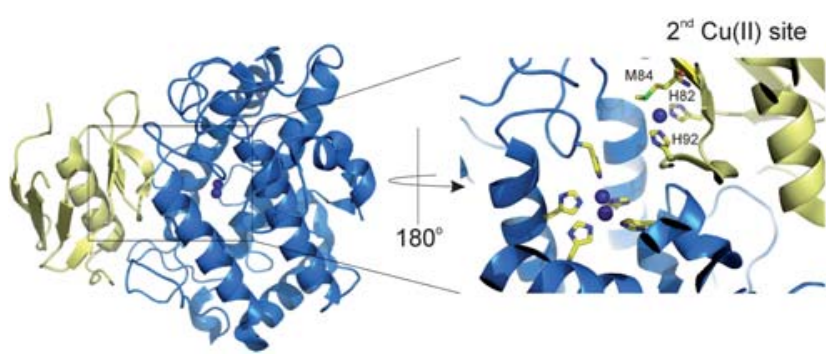

Fig. 9 Tyrosinase from $S$. castaneoglobisporus and its chaperone protein. The X-ray crystal structure of the copper loaded (blue spheres) tyrosinase (blue) in complex with its melC1-like chaperone protein (gold) (pdb entry $1 \mathrm{WX} 2$ ). ${ }^{103}$ Tyrosinase adopts a $\alpha$-helical structure with a core fold consisting of a four-helix bundle housing the Type 3 copper site. The melC1-like protein has a fold homologous to a $\mathrm{SH} 2$ domain. A zoomed-in region of the copper-loaded cupric binding site in the melC1-like protein (pdb entry 2AHK). ${ }^{103}$ The ligands to the copper at this site are indicated. His 82 is also involved in binding copper at the first site, and is therefore considered a critical residue in the sequential transfer of copper in assembly of the tyrosinase active site. site is completed by a second His and the thioether of a Met (Fig. 9). In combination with biochemical data, it is has been proposed that a sequential mechanism of copper transfer occurs, whereby the first site transfers its cargo to the second site, with His 82 a key residue, followed by transfer to the apo-tyrosinase. ${ }^{103}$ Delivery of copper to apo-enzymes or proteins outside of the cytosolic environment in prokaryotes is most often mediated through chaperones whose ligand sets favor the binding of $\mathrm{Cu}(\mathrm{I})$ ions $^{58}$ (Fig. 9). MelC1 on the other hand has nitrogen donors at the first and second copper binding sites which favor a higher affinity for $\mathrm{Cu}(\mathrm{II})$ coordination over $\mathrm{Cu}(\mathrm{I})$. This suggests that copper transfer most likely takes place during or after membrane crossing in the more oxidizing surroundings of the extracellular environment.

\subsection{Copper efflux systems and transcriptional regulators}

Given its toxicity and low intracellular requirement for $\mathrm{Cu}(\mathrm{I})$, copper uptake into the cytosol in bacteria is not well characterized. Conversely, when copper levels change upon stress conditions, bacteria are known to express efflux systems or in some cases metallothioneins to expel or sequester potentially deleterious $\mathrm{Cu}(\mathrm{I})$ ions. ${ }^{107} \mathrm{~A}$ bacterial metallothionein, specific for copper, has most recently been identified in the actinobacteria M. tuberculosis. ${ }^{108}$ The regulated expression of $\mathrm{Cu}(\mathrm{I})$ efflux systems is controlled through metalloregulatory proteins, that sense metal availability within their environment. From the blueprint of copper proteins in S. coelicolor (Fig. 4), a number of putative proteins have been identified which have been assigned roles in copper homeostasis based on homologues in other bacteria.

In the cytoplasm of the Gram-positive bacteria B. subtilis and Enterococcus hirae, a specific efflux system exists encoded by the copZ $A$ and the cop $Y Z A B$ operon respectively, which are induced upon response to an increase in copper levels. ${ }^{109,110} \mathrm{CopZ}$ coordinates $\mathrm{Cu}(\mathrm{I})$ via two Cys residues (Fig. 3B) and acts as a chaperone to CopA, a CPx-type efflux ATPase. In S. coelicolor two ORFs are identified which encode a CopZ-like protein, both of which precede a gene for a P-type ATPase (SCO1046 and SCO2731) (Fig. 4). Another P-type ATPase has been identified in $S$. coelicolor (SCO0860) but no CopZ gene precedes it, nor is there a recognizable copper binding motif nearby. In B. subtilis the metalloregulatory protein, or metal sensor, controlling the expression of the $\operatorname{cop} Z A$ operon has recently been identified as YvgZ. ${ }^{111}$ This is a CsoR (copper-sensitive operon) orthologue belonging to a new member of metalloregulators originally identified in the actinobacteria $M$. tuberculosis. ${ }^{112}$ In B. subtilis and $M$. tuberculosis $\mathrm{Cso} \mathrm{R}$ acts as a copper specific repressor binding to the promoter region of a copper efflux operon. ${ }^{111,112}$ Structural characterization of $M$. tuberculosis CsoR has revealed a homodimer with a $\mathrm{Cu}(\mathrm{I})$-binding motif consisting of two Cys residues and one His residue that adopt a trigonal copper coordination geometry (Fig. 3B). The binding affinity per monomer for $\mathrm{Cu}(\mathrm{I})$ has been estimated for the CsoRs from M. tuberculosis and B. subtilis, with lower limits for $K_{\mathrm{Cu}}$ of $\geq 10^{19} \mathrm{M}^{-1}$ and $\geq 10^{21} \mathrm{M}^{-1}$ determined, respectively. ${ }^{54,113}$

In $S$. coelicolor SCO4136 is predicted to encode for a putative CsoR protein, but from analysis of the gene environment it appears not to be part of either of the two copZA-like loci, as 
observed in B. subtilis or M. tuberculosis. In fact, the surrounding genomic environment shows no known (or candidate) copper resistance genes and instead, $\mathrm{SCO} 4136$ is clustered with genes encoding for proteins that are strong candidates to participate in inorganic phosphate transport. ${ }^{60}$ Therefore the question arises of whether P4136 is a copper-specific sensor protein. Identification from sequence alone as to which metal a sensor protein binds is notoriously difficult. However, conserved residues at several signature positions designated $\mathrm{W}-\mathrm{X}-\mathrm{Y}-\mathrm{Z}$ have been identified in the CsoR/RcnR family, of which the latter has a preference for $\mathrm{Ni}(\mathrm{II}) / \mathrm{Co}(\mathrm{II}){ }^{114,115}$ For $\mathrm{Cu}(\mathrm{I})$-sensing CsoRs a W-X-Y-Z fingerprint of $\mathrm{x}$-Cys-His-Cys has been identified (where $\mathrm{x}$ is any aminoacid). This signature is present in the $\mathrm{P} 4136$ sequence, and despite not being localized near copper resistance genes P4136 is strongly favored to bind $\mathrm{Cu}(\mathrm{I})$ and act as $\mathrm{Cu}(\mathrm{I})$ sensor in $S$. coelicolor.

A tight link between phosphate availability and development in Streptomyces species has been suggested, ${ }^{116}$ and the biosynthesis of many different types of antibiotics and other secondary metabolites are regulated by inorganic phosphate. ${ }^{117}$ It has also been proposed that polyphosphate sequesters heavy metals, thereby reducing their intracellular concentration and toxicity. ${ }^{118}$ Van Veen ${ }^{119}$ has shown that the inorganic phosphate transport system (Pit) in E. coli and Acinetobacter johnsonii can reversibly transport metal phosphates. Furthermore, in Acidithiobacillus ferrooxidans elevated copper levels are sequestered by polyphosphates and exported via Pit. ${ }^{120}$ In $S$. coelicolor, the genes SCO4138 and SCO4137 constitute a bicistronic transcript, in which SCO4138 encodes for a Pit and SCO4137 is an accessory protein. It is therefore an attractive possibility that $\mathrm{P} 4136$ may be involved in regulating this bicistronic transcript under copper stress conditions.

A second CsoR orthologue is identified in $S$. coelicolor, SCO0620, which contains a $\mathrm{x}$-Cys-X-Cys W-X-Y-Z fingerprint and is located in the cytosolic environment. Based on this fingerprint, $\mathrm{P} 0620$ is unlikely to be $\mathrm{a} \mathrm{Cu}(\mathrm{I})$ sensor, as substitution of the $\mathrm{Cu}(\mathrm{I}) \mathrm{His}$ ligand has been shown to render CsoR inactive as a $\mathrm{Cu}(\mathrm{I})$ sensor. ${ }^{54}$ Instead, a function for members with this $\mathrm{W}-\mathrm{X}-\mathrm{Y}-\mathrm{Z}$ fingerprint may be in non-metal sensing of oxidative stress or antibiotic resistance. ${ }^{114}$

\subsection{The role of Sco1 in copper-dependent development}

Bacteria have relatively little control over the passing of metal ions through pores in the bacterial outer membrane. Thus metal ions in the periplasm or extracellular space are less well regulated than in the cytosolic environment. In S. lividans, Tat mutants that are defective in secretion through the Tat pathway are blocked in development and cannot switch to the production of aerial mycelium, but can be rescued through the addition of high concentrations of copper, strongly implying that enzymes with copper co-factors and copper-trafficking proteins are involved in development.

In S. coelicolor, SCO3966 encodes for a protein homologous to the copper chaperone protein Scol in eukaryotes, which is likely responsible for the metallation of the binuclear $\mathrm{Cu}_{\mathrm{A}}$ site of cytochrome c oxidase $(\mathrm{CcO})$. In prokaryotes, $\mathrm{Sco} 1$ also carries out metallation of the $\mathrm{Cu}_{\mathrm{A}}$ site, but other roles, including copper transport to other enzymes/proteins, have been implied. The ORF immediately downstream of 3966 has similarity to a $\mathrm{Cu}(\mathrm{I})$ chaperone (DR1885) identified in Deinococcus radiodurans. ${ }^{49}$ This chaperone is unique to bacterial genomes, with a recent study highlighting its role in the assembly of the $\mathrm{Cu}_{\mathrm{A}}$ site in $\mathrm{CcO}$ in tandem with Sco1 in Thermus thermophilus. ${ }^{121}$

A very recent study has identified SCO3966 to have a direct link between development and copper-trafficking in S. lividans. ${ }^{122}$ A null mutant of the copper chaperone Sco1 in S. lividans has a bld phenotype, i.e. the developmental switch from vegetative to aerial mycelium is blocked, and exhibits no $\mathrm{CcO}$ activity (Fig. 10). This suggests that $\mathrm{CcO}$ is essential for development, but a $\mathrm{CcO}$ null mutant (genes for subunit I and II replaced by an antibiotic resistance cassette) is viable and not defective in development. ${ }^{122}$ These different phenotypes point towards a second chaperone function of Scol in addition to the assembly of the $\mathrm{Cu}_{\mathrm{A}}$ site in $\mathrm{CcO}$. The ability to restore development by the addition of copper to the Scol variant suggests that a copper enzyme is a key component in the development pathway in Streptomyces. At present a chaperone partner for Scol is speculative, but a strong candidate is the radical copper oxidase

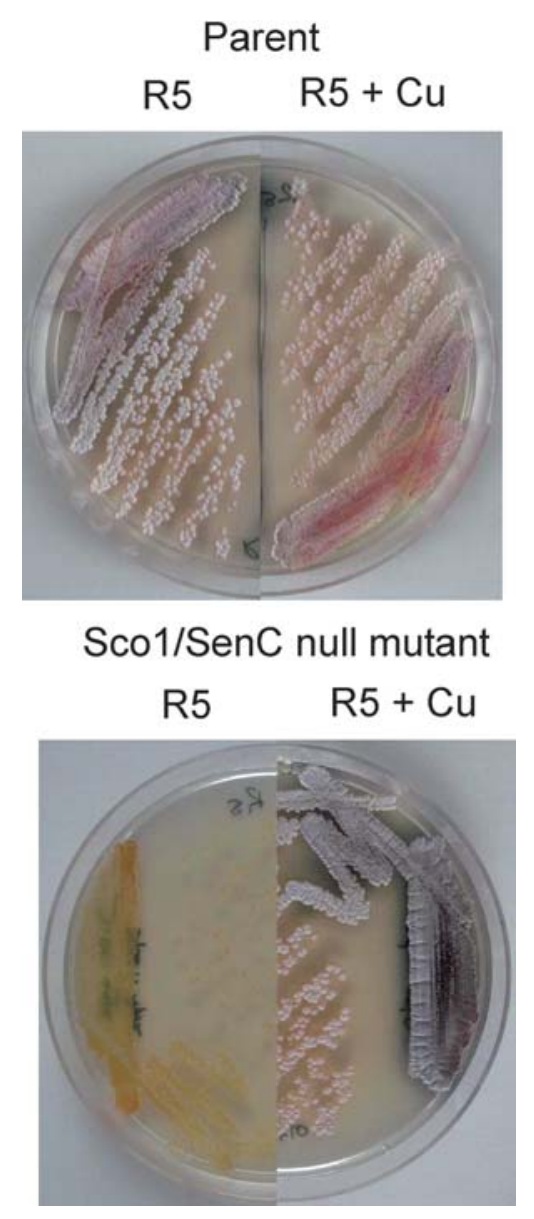

Fig. 10 A role for Sco1 in Streptomyces development. The parent strain and the Sco1/SenC null mutant were grown on R5 medium $\left(0.2 \mu \mathrm{M} \mathrm{Cu}^{2+}\right)$ and $\mathrm{R} 5$ medium containing $10 \mu \mathrm{M} \mathrm{Cu}^{2+}$. The null mutant is only capable of producing an aerial mycelium and spores on this medium when extra copper is added. This demonstrates that Scol is conditionally required for morphological development. With sufficiently high $\mathrm{Cu}^{2+}$ concentrations its activity as copper chaperone is not strictly needed, suggesting that the metallation of the target enzymes proceeds spontaneously. 
(SCO2837) in which a knockout in S. lividans is unable to be rescued by elevated copper concentrations. ${ }^{122}$ SCO2837 is found amongst genes encoding proteins that are required for cell wall and sugar synthesis and therefore important for organism development. ${ }^{100}$ The possibility that Scol has other targets in Streptomyces other than $\mathrm{CcO}$ is intriguing, and it remains to be seen whether this is also the case for other bacterial Sco proteins.

\section{Conclusions and future perspectives}

From this review of development and natural product production involving copper enzymes and proteins in streptomycetes, it is obvious that very little is known and that further research in this area is needed. The function of many of the copper enzymes identified in $S$. coelicolor is not clear, although most of them have been assigned to a "protein family" as outlined and discussed in this review. Furthermore, the copper homeostasis and trafficking in streptomycetes is to a large extent an unexplored field, and how both morphological and physiological development are affected by copper bioavailability remains to be discovered. Further characterization of the role of Scol will hopefully begin to address this issue.

The biochemical characterization of the copper enzymes requires the production of large quantities of protein. In general, this could be obtained from expression in standard hosts such as E. coli, although some proteins have been shown to be expressed poorly or to be expressed only as a pre-protein lacking the co-factor, in this case copper. Powerful native expression systems in a Streptomyces host are needed desperately and their development is currently in progress (EV, unpublished data). A challenge will also be to translate the in vitro data from emerging biochemical studies with the in vivo situation. An example touched on briefly in this review is the radical copper oxidase expressed from SCO2837. This enzyme has been demonstrated to preferentially catalyze oxidation of primary alcohols to the corresponding aldehyde but its physiological substrate and function is not elucidated (yet). ${ }^{101}$ This is also the case for SLAC. ${ }^{\mathbf{8 4 , 8 5}}$

From the natural product point of view, studies on Corynebacterium glutamicum suggest that oxidative phosphorylation and thus the copper-containing $\mathrm{CcO}$ provides an attractive target for improving production of natural products. ${ }^{123-125}$ Whether this is also the case in Streptomyces remains to be seen, but preliminary data with $\mathrm{CcO}$ mutants in S. lividans suggest that it is an interesting approach (E. Vijgenboom, unpublished data).

An interesting hypothesis has been revived recently by Davies and coworkers which suggests that most secondary metabolites are in fact signaling molecules in the microbial habitat and not (as assumed for some time) waste products or antibacterials, antifungals etc. ${ }^{\mathbf{2 6 , 1 2 6}}$ This hypothesis is supported by the demonstrated function of phenazine derivatives in signaling in $P$. aeruginos $a^{27,127}$ and the effect of sub-inhibitory concentrations of antibiotics on transcription. ${ }^{\mathbf{1 2 8}}$ Since most signaling molecules are present in small amounts, different experimental approaches are needed to detect the low levels of new useful secondary metabolites. To this end, dedicated expression hosts will have to be designed to isolate the large quantities of these compounds needed for their characterization.

\section{References}

1 A. Manteca, D. Claessen, C. Lopez-Iglesias and J. Sanchez, FEMS Microbiol. Lett., 2007, 274, 118-125.

2 A. Manteca and J. Sanchez, Appl. Environ. Microbiol., 2009, 75, 2920-2924.

3 A. Manteca, U. Mader, B. A. Connolly and J. Sanchez, Proteomics, 2006, 6, 6008-6022.

4 A. Manteca, M. Fernandez and J. Sanchez, Microbiology, 2005, 151, 3689-3697.

5 E. E. Noens, V. Mersinias, J. Willemse, B. A. Traag, E. Laing, K. F. Chater, C. P. Smith, H. K. Koerten and G. P. van Wezel, Mol. Microbiol., 2007, 64, 1244-1259.

6 A. Parashar, K. R. Colvin, D. R. Bignell and B. K. Leskiw, J. Bacteriol., 2009, 191, 2541-2550.

7 M. J. Bibb, V. Molle and M. J. Buttner, J. Bacteriol., 2000, 182, 4606- 4616.

8 W. Li, J. Wu, W. Tao, C. Zhao, Y. Wang, X. He, G. Chandra, X. Zhou, Z. Deng, K. F. Chater and M. Tao, FEMS Microbiol. Lett., 2007, 266, 20-28.

9 K. F. Chater, Philos. Trans. R. Soc. London, Ser. B, 2006, 361, 761768.

10 D. W. Kim, A. Hesketh, E. S. Kim, J. Y. Song, D. H. Lee, I. S. Kim, K. F. Chater and K. J. Lee, Mol. Microbiol., 2008, 70, 11801193.

11 N. K. Davis and K. F. Chater, Mol. Microbiol., 1990, 4, 1679-1691.

12 A. M. Gehring, J. R. Nodwell, S. M. Beverley and R. Losick, Proc. Natl. Acad. Sci. U. S. A., 2000, 97, 9642-9647.

13 N. J. Ryding, M. J. Bibb, V. Molle, K. C. Findlay, K. F. Chater and M. J. Buttner, J. Bacteriol., 1999, 181, 5419-5425.

14 S. Kawamoto and J. C. Ensign, Actinomycetologica, 1995, 9, 136151.

15 G. P. van Wezel, J. van der Meulen, S. Kawamoto, R. G. Luiten, H. K. Koerten and B. Kraal, J. Bacteriol., 2000, 182, 5653-5662.

16 B. A. Traag and G. P. van Wezel, Antonie van Leeuwenhoek, 2008, 94, 85-97.

17 D. Claessen, R. Rink, W. de Jong, J. Siebring, P. de Vreugd, F. G. Boersma, L. Dijkhuizen and H. A. Wosten, Genes Dev., $2003,17,1714-1726$.

18 D. Claessen, I. Stokroos, H. J. Deelstra, N. A. Penninga, C. Bormann, J. A. Salas, L. Dijkhuizen and H. A. Wosten, Mol. Microbiol., 2004, 53, 433-443.

19 D. Claessen, W. de Jong, L. Dijkhuizen and H. A. Wosten, Trends Microbiol., 2006, 14, 313-319.

20 A. L. Demain, Biotechnol. Adv., 2000, 18, 499-514.

21 G. L. Challis and D. A. Hopwood, Proc. Natl. Acad. Sci. U. S. A., 2003, 100(Suppl. 2), 14555-14561.

22 S. Rigali, F. Titgemeyer, S. Barends, S. Mulder, A. W. Thomae, D. A. Hopwood and G. P. van Wezel, EMBO Rep., 2008, 9, 670675.

23 M. J. Bibb, Curr. Opin. Microbiol., 2005, 8, 208-215.

24 D. Kallifidas, B. Pascoe, G. A. Owen, C. M. Strain-Damerell, H. J. Hong and M. S. Paget, J. Bacteriol., 2010, 192, 608-611.

25 A. Hesketh, H. Kock, S. Mootien and M. Bibb, Mol. Microbiol., 2009, 74, 1427-1444.

26 G. Yim, H. H. Wang and J. Davies, Philos. Trans. R. Soc. London, Ser. B, 2007, 362, 1195-1200.

27 L. E. Dietrich, T. K. Teal, A. Price-Whelan and D. K. Newman, Science, 2008, 321, 1203-1206.

28 S. Horinouchi, Biosci., Biotechnol., Biochem., 2007, 71, 283-299.

29 N. H. Hsiao, S. Nakayama, M. E. Merlo, M. de Vries, R. Bunet, S. Kitani, T. Nihira and E. Takano, Chem. Biol., 2009, 16, 951-960.

30 Z. Kiss, A. C. Ward, Z. Birko, K. F. Chater and S. Biro, Int. J. Syst. Evol. Microbiol., 2008, 58, 1029-1031.

31 Z. Birko, S. Bialek, K. Buzas, E. Szajli, B. A. Traag, K. F. Medzihradszky, S. Rigali, E. Vijgenboom, A. Penyige, Z. Kele, G. P. van Wezel and S. Biro, Mol. Cell. Proteomics, 2007, 6, 1248-1256.

32 D. Brekasis and M. S. Paget, EMBO J., 2003, 22, 4856-4865.

33 M. S. Paget, J. G. Kang, J. H. Roe and M. J. Buttner, EMBO J., 1998, 17, 5776-5782.

34 V. Molle, W. J. Palframan, K. C. Findlay and M. J. Buttner, J. Bacteriol., 2000, 182, 1286-1295.

35 J. A. Soliveri, J. Gomez, W. R. Bishai and K. F. Chater, Microbiology, 2000, 146(Pt 2), 333-343. 
36 P. Jakimowicz, M. R. Cheesman, W. R. Bishai, K. F. Chater, A. J. Thomson and M. J. Buttner, J. Biol. Chem., 2005, 280, 83098315.

37 S. K. Garg, M. Suhail Alam, V. Soni, K. V. Radha Kishan and P. Agrawal, Protein Expression Purif., 2007, 52, 422-432.

38 M. S. Alam, S. K. Garg and P. Agrawal, Mol. Microbiol., 2007, 63, $1414-1431$.

39 J. C. Crack, C. D. den Hengst, P. Jakimowicz, S. Subramanian, M. K. Johnson, M. J. Buttner, A. J. Thomson and N. E. Le Brun, Biochemistry, 2009, 48, 12252-12264.

40 K. Ueda, Y. Tomaru, K. Endoh and T. Beppu, J. Antibiot. (Tokyo), 1997, 50, 693-695.

41 B. J. Keijser, G. P. van Wezel, G. W. Canters, T. Kieser and E. Vijgenboom, J. Mol. Microbiol. Biotechnol., 2000, 2, 565-574.

42 K. Schaerlaekens, L. Van Mellaert, E. Lammertyn, N. Geukens and J. Anne, Microbiology, 2004, 150, 21-31.

43 D. A. Widdick, K. Dilks, G. Chandra, A. Bottrill, M. Naldrett, M. Pohlschroder and T. Palmer, Proc. Natl. Acad. Sci. U. S. A., 2006, 103, 17927-17932.

44 K. Marbach, J. Fernandez-Larrea and U. Stahl, Curr. Genet., 1994, 26, 184-186.

45 C. Borghouts and H. D. Osiewacz, Mol. Gen. Genet., 1998, 260, 492502.

46 A. Sykes, Adv. Inorg. Chem., 1991, 36, 377-408.

47 S. Tottey, D. R. Harvie and N. J. Robinson, Acc. Chem. Res., 2005, 38, 775-783.

48 F. Arnesano, L. Banci, I. Bertini and A. R. Thompsett, Structure, 2002, 10, 1337-1347.

49 L. Banci, I. Bertini, S. Ciofi-Baffoni, E. Katsari, N. Katsaros, K. Kubicek and S. Mangani, Proc. Natl. Acad. Sci. U. S. A., 2005, 102, 3994-3999.

50 L. A. Finney and T. V. O'Halloran, Science, 2003, 300, 931-936.

51 T. V. O'Halloran and V. C. Culotta, J. Biol. Chem., 2000, 275, 25057-25060.

52 J. C. Williams, C. Sue, G. S. Banting, H. Yang, D. M. Glerum, W. A. Hendrickson and E. A. Schon, J. Biol. Chem., 2005, 280, $15202-15211$.

53 D. L. Huffman and T. V. O'Halloran, Annu. Rev. Biochem., 2001, 70, 677-701.

54 T. Liu, A. Ramesh, Z. Ma, S. K. Ward, L. Zhang, G. N. George, A. M. Talaat, J. C. Sacchettini and D. P. Giedroc, Nat. Chem. Biol., 2007, 3, 60-68.

55 R. A. Pufahl, C. P. Singer, K. L. Peariso, S. J. Lin, P. J. Schmidt, C. J. Fahrni, V. C. Culotta, J. E. Penner-Hahn and T. V. O'Halloran, Science, 1997, 278, 853-856.

56 C. Rensing and G. Grass, FEMS Microbiol. Rev., 2003, 27, 197-213.

57 M. Solioz and J. V. Stoyanov, FEMS Microbiol. Rev., 2003, 27, $183-$ 195.

58 A. V. Davis and T. V. O'Halloran, Nat. Chem. Biol., 2008, 4, 148151.

59 C. Andreini, L. Banci, I. Bertini and A. Rosato, J. Proteome Res., 2008, 7, 209-216.

60 S. D. Bentley, K. F. Chater, A. M. Cerdeno-Tarraga, G. L. Challis, N. R. Thomson, K. D. James, D. E. Harris, M. A. Quail, H. Kieser, D. Harper, A. Bateman, S. Brown, G. Chandra, C. W. Chen, M. Collins, A. Cronin, A. Fraser, A. Goble, J. Hidalgo, T. Hornsby, S. Howarth, C. H. Huang, T. Kieser, L. Larke, L. Murphy, K. Oliver, S. O’Neil, E. Rabbinowitsch, M. A. Rajandream, K. Rutherford, S. Rutter, K. Seeger, D. Saunders, S. Sharp, R. Squares, S. Squares, K. Taylor, T. Warren, A. Wietzorrek, J. Woodward, B. G. Barrell, J. Parkhill and D. A. Hopwood, Nature, 2002, 417, 141-147.

61 J. A. Worrall, M. C. Machczynski, B. J. Keijser, G. di Rocco, S. Ceola, M. Ubbink, E. Vijgenboom and G. W. Canters, J. Am. Chem. Soc., 2006, 128, 14579-14589.

62 S. Hayashi and H. C. Wu, J. Bioenerg. Biomembr., 1990, 22, 451471.

63 S. Inouye, T. Franceschini, M. Sato, K. Itakura and M. Inouye, EMBO J., 1983, 2, 87-91.

64 S. Pollitt, S. Inouye and M. Inouye, J. Biol. Chem., 1986, 261, 18351837.

65 M. Le Roes-Hill, C. Goodwin and S. Burton, Trends Biotechnol., 2009, 27, 248-258.

66 G. H. Jones, Antimicrob. Agents Chemother., 2000, 44, 13221327.
67 A. W. Smith, A. Camara-Artigas, M. Wang, J. P. Allen and W. A. Francisco, Biochemistry, 2006, 45, 4378-4387.

68 C. E. Barry, 3rd, P. G. Nayar and T. P. Begley, Biochemistry, 1989, 28, 6323-6333.

69 E. I. Solomon, U. M. Sundaram and T. E. Machonkin, Chem. Rev., 1996, 96, 2563-2606.

70 H. A. Choy and G. H. Jones, Arch. Biochem. Biophys., 1981, 211, 5565.

71 J. C. Freeman, P. G. Nayar, T. P. Begley and J. J. Villafranca, Biochemistry, 1993, 32, 4826-4830.

72 V. Bernan, D. Filpula, W. Herber, M. Bibb and E. Katz, Gene, 1985, 37, 101-110.

73 L. Y. Chen, M. Y. Chen, W. M. Leu, T. Y. Tsai and Y. H. Lee, J. Biol. Chem., 1993, 268, 18710-18716.

74 W. M. Leu, L. Y. Chen, L. L. Liaw and Y. H. Lee, J. Biol. Chem., 1992, 267, 20108-20113.

75 L. Y. Chen, W. M. Leu, K. T. Wang and Y. H. Lee, J. Biol. Chem., 1992, 267, 20100-20107.

76 P. A. Riley, Int. J. Biochem. Cell Biol., 1997, 29, 1235-1239.

77 C. W. van Gelder, W. H. Flurkey and H. J. Wichers, Phytochemistry, 1997, 45, 1309-1323.

78 A. Sanchez-Ferrer, J. N. Rodriguez-Lopez, F. Garcia-Canovas and F. Garcia-Carmona, Biochim. Biophys. Acta, Protein Struct. Mol. Enzymol., 1995, 1247, 1-11.

79 S. Y. Seo, V. K. Sharma and N. Sharma, J. Agric. Food Chem., 2003, 51, 2837-2853.

80 G. Prota, Pigm. Cell Res., 2000, 13, 283-293.

81 N. Kollias, R. M. Sayre, L. Zeise and M. R. Chedekel, J. Photochem. Photobiol., B, 1991, 9, 135-160.

82 H. Y. Yang and C. W. Chen, PLoS One, 2009, 4, e7462.

83 H. Suzuki, Y. Furusho, T. Higashi, Y. Ohnishi and S. Horinouchi, J. Biol. Chem., 2006, 281, 824-833.

84 M. C. Machczynski, E. Vijgenboom, B. Samyn and G. W. Canters, Protein Sci., 2004, 13, 2388-2397.

85 T. Skalova, J. Dohnalek, L. H. Ostergaard, P. R. Ostergaard, P. Kolenko, J. Duskova, A. Stepankova and J. Hasek, J. Mol. Biol., 2009, 385, 1165-1178.

86 M. E. Murphy, S. Turley and E. T. Adman, J. Biol. Chem., 1997, 272, 28455-28460.

87 E. I. Solomon, R. Sarangi, J. S. Woertink, A. J. Augustine, J. Yoon and S. Ghosh, Acc. Chem. Res., 2007, 40, 581-591.

88 A. W. Tepper, S. Milikisyants, S. Sottini, E. Vijgenboom, E. J. Groenen and G. W. Canters, J. Am. Chem. Soc., 2009, 131, $11680-11682$.

89 T. Skalova, J. Dohnalek, L. H. Ostergaard, P. R. Ostergaard, P. Kolenko, J. Duskova and J. Hasek, Acta Crystallogr., Sect. F: Struct. Biol. Cryst. Commun., 2007, 63, 1077-1079.

90 J. Gallaway, I. Wheeldon, R. Rincon, P. Atanassov, S. Banta and S. C. Barton, Biosens. Bioelectron., 2008, 23, 1229-1235.

91 C. Dennison, G. W. Canters, S. De Vries, E. Vijgenboom and R. J. Van Spanning, Adv. Inorg. Chem., 1998, 45, 351- 407.

92 C. Dennison, Dalton Trans., 2005, 3436-3442.

93 C. Dennison, Nat. Prod. Rep., 2008, 25, 15-24.

94 T. van Houwelingen, G. W. Canters, G. Stobbelaar, J. A. Duine, J. Frank, Jr. and A. Tsugita, Eur. J. Biochem., 1985, 153, 75-80.

95 K. A. Gray, D. B. Knaff, M. Husain and V. L. Davidson, FEBS Lett., 1986, 207, 239-242.

96 N. M. Marshall, D. K. Garner, T. D. Wilson, Y. G. Gao, H. Robinson, M. J. Nilges and Y. Lu, Nature, 2009, 462, 113-116.

97 J. W. Whittaker, Arch. Biochem. Biophys., 2005, 433, 227-239.

98 J. W. Whittaker, Chem. Rev., 2003, 103, 2347-2363.

99 N. Ito, S. E. Phillips, C. Stevens, Z. B. Ogel, M. J. McPherson, J. N. Keen, K. D. Yadav and P. F. Knowles, Nature, 1991, 350, $87-90$.

100 H. Xu, K. F. Chater, Z. Deng and M. Tao, J. Bacteriol., 2008, 190, 4971-4978.

101 M. M. Whittaker and J. W. Whittaker, Arch. Biochem. Biophys., 2006, 452, 108-118.

102 J. S. Hahn, S. Y. Oh and J. H. Roe, J. Bacteriol., 2002, 184, 5214 5222 .

103 Y. Matoba, T. Kumagai, A. Yamamoto, H. Yoshitsu and M. Sugiyama, J. Biol. Chem., 2006, 281, 8981-8990.

104 W. Xu, S. C. Harrison and M. J. Eck, Nature, 1997, 385, 595-602.

105 W. P. J. Gaykema, W. G. J. Hol, J. M. Vereijken, N. M. Soeter, H. J. Bak and J. J. Beintema, Nature, 1984, 309, 23-29. 
106 T. Klabunde, C. Eicken, J. C. Sacchettini and B. Krebs, Nat. Struct. Biol., 1998, 5, 1084-1090.

107 C. A. Blindauer, M. D. Harrison, A. K. Robinson, J. A. Parkinson, P. W. Bowness, P. J. Sadler and N. J. Robinson, Mol. Microbiol., $2002,45,1421-1432$

108 B. Gold, H. Deng, R. Bryk, D. Vargas, D. Eliezer, J. Roberts, X. Jiang and C. Nathan, Nat. Chem. Biol., 2008, 4, 609-616.

109 A. Gaballa and J. D. Helmann, BioMetals, 2003, 16, 497-505.

110 D. Magnani and M. Solioz, BioMetals, 2005, 18, 407-412.

111 G. T. Smaldone and J. D. Helmann, Microbiology, 2007, 153, 4123-4128.

112 D. P. Giedroc and A. I. Arunkumar, Dalton Trans., 2007, $3107-$ 3120.

113 Z. Ma, D. M. Cowart, R. A. Scott and D. P. Giedroc, Biochemistry, $2009,48,3325-3334$

114 Z. Ma, F. E. Jacobsen and D. P. Giedroc, Chem. Rev., 2009, 109, $4644-4681$.

115 J. S. Iwig, S. Leitch, R. W. Herbst, M. J. Maroney and P. T. Chivers, J. Am. Chem. Soc., 2008, 130, 7592-7606.

116 M. Diaz, A. Esteban, J. M. Fernandez-Abalos and R. I. Santamaria, Microbiology, 2005, 151, 2583-2592.

117 J. F. Martin, J. Bacteriol., 2004, 186, 5197-5201.

118 H. Aiking, A. Stijnman, C. van Garderen, H. van Heerikhuizen and J. van't Riet, Appl. Environ. Microbiol., 1984, 47, 374-377.

119 H. W. van Veen, Antonie van Leeuwenhoek, 1997, 72, 299-315.
120 S. Alvarez and C. A. Jerez, Appl. Environ. Microbiol., 2004, 70, 51775182.

121 L. A. Abriata, L. Banci, I. Bertini, S. Ciofi-Baffoni, P. Gkazonis, G. A. Spyroulias, A. J. Vila and S. Wang, Nat. Chem. Biol., 2008, 4, 599-601.

122 S. Bialek, B. J. Keijser, I. Dragan, B. Florea, R. van der Heijden, G. P. van Wezel, P. Hensbergen and E. Vijgenboom, 2010.

123 M. Bott and A. Niebisch, J. Biotechnol., 2003, 104, 129-153.

124 A. Kabus, A. Niebisch and M. Bott, Appl. Environ. Microbiol., 2007, 73, $861-868$.

125 M. K. Toma, E. Shvinka Iu, M. P. Ruklisha, A. K. Sakse and L. A. Baburin, Prikl. Biokhim. Mikrobiol., 1984, 20, 95-100.

126 G. Yim, H. H. Wang and J. Davies, Int. J. Med. Microbiol., 2006, 296, 163-170.

127 L. E. Dietrich, A. Price-Whelan, A. Petersen, M. Whiteley and D. K. Newman, Mol. Microbiol., 2006, 61, 1308-1321.

128 W. H. Tsui, G. Yim, H. H. Wang, J. E. McClure, M. G. Surette and J. Davies, Chem. Biol., 2004, 11, 1307-1316.

129 F. Arnesano, L. Banci, I. Bertini, S. Mangani and A. R. Thompsett, Proc. Natl. Acad. Sci. U. S. A., 2003, 100, 3814-3819.

130 K. Piontek, M. Antorini and T. Choinowski, J. Biol. Chem., 2002, 277, 37663-37669.

131 O. Emanuelsson, S. Brunak, G. von Heijne and H. Nielsen, Nat. Protoc., 2007, 2, 953-971. 